\title{
THE OCCURRENCE OF EXTREME MONTHLY TEMPERATURES AND PRECIPITATION IN TWO GLOBAL REGIONS
}

\author{
A Thesis presented to the Faculty of the Graduate School at the \\ University of Missouri-Columbia
}

\begin{abstract}
In Partial Fulfillment of the Requirements for the Degree Master of Science
\end{abstract}

by MAX JAMES NUNES

Dr. Anthony Lupo, Thesis Supervisor

JULY 2017 
The undersigned, appointed by the Dean of the Graduate School, have examined the thesis entitled:

\title{
THE OCCURRENCE OF EXTREME MONTHLY TEMPERATURE AND PRECIPITATION IN TWO GLOBAL REGIONS
}

\author{
Presented by: Max James Nunes \\ A candidate for the degree of Master of Science
}

And hereby certify that in their opinion it is worthy of acceptance.

Dr. Anthony R. Lupo, Professor

Dr. Patrick E. Guinan, Associate Professor

Dr. Bohumil M. Svoma, Assistant Professor

Dr. Jeffrey D. Wood, Assistant Research Professor 
This thesis is dedicated to my parents, Mr. Paul and Mrs. Nancy Nunes, whom have always believed in me. Without them, the opportunity to write this paper would not be possible. I am forever appreciative of their love and support. 


\section{ACKNOWLEDGEMENTS}

I wish to express my deepest gratitude to Dr. Anthony Lupo for being a great advisor and motivator. I would not have come as far as I have today if not for his longstanding belief in me. His help with the methodologies used in this study were at a tremendous scale. I would also like to thank my committee members: Dr. Anthony Lupo, Dr. Patrick Guinan, Dr. Bohumil Svoma, and Dr. Jeffrey Wood for taking the time and effort to be on my committee. My other undergraduate/graduate professors, Dr. Patrick Market, Dr. Bohumil Svoma, and Dr. Neil Fox, also deserve recognition for their contributions to my academic career. All of their guidance as professionals is greatly motivational and influencing. Lastly, I wish to thank my fellow graduate students of Atmospheric Science, my peers, who gave me more aid than they realize. 
TABLE OF CONTENTS

ACKNOWLEDGEMENTS..............................................ii

LIST OF FIGURES $\ldots \ldots \ldots \ldots \ldots \ldots \ldots \ldots \ldots \ldots \ldots \ldots \ldots \ldots \ldots \ldots \ldots \ldots \ldots$

LIST OF TABLES...................................................viii

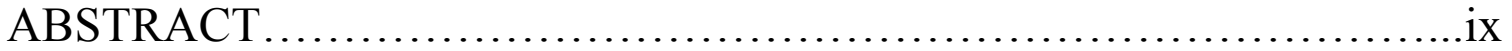

CHAPTER 1. INTRODUCTION .......................................1

1.1 Objectives.............................................2

1.2 Statement of Thesis..........................................

CHAPTER 2. DATA AND METHODOLOGY .........................4

2.1 Data Sources............................................4

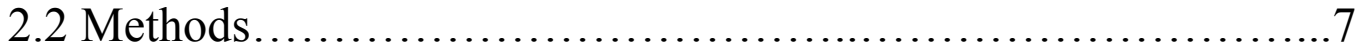

CHAPTER 3. STATISTICS .......................................11

3.1 Climatological Analysis..................................11

3.2 Interannual and Interdecadal Variability......................13

3.3 Temperature Analysis of cUSA and swRUS ..................16 CHAPTER 4. DECEMBER 1889 AND MARCH 2012 CASE STUDIES..20

4.1 Conditions over North America.............................20

4.2 Atmospheric Blocking...................................23 
CHAPTER 5. DISCUSSION ......................................28

5.1 ENSO Phase Patterns....................................28

5.2 Blocking Phenomena....................................29

5.3 Trending Warm Events....................................30

CHAPTER 6. CONCLUSIONS ..................................... 32

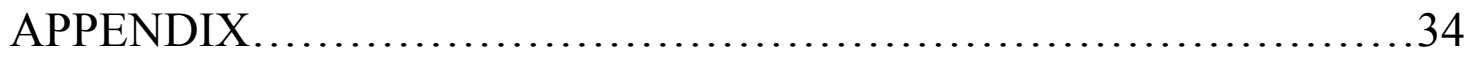

REFERENCES.................................................55 


\section{LIST OF FIGURES}

Figure 2.1. Map of Columbia in the cUSA study region.

Figure 2.2. Map of swRUS Belgorod Oblast study region. Shows the relative location (set) within Russia; provided by Bradley University.

Figure 2.3. El Niño Southern Oscillation Index time series 1950 - present. Supplied from the NOAA Physical Sciences Division - located at the University of Colorado.

Figure 4.1. The observed temperature for December 1889 and March 2012 in the cUSA $\left({ }^{\circ} \mathrm{C}\right)$ compared to the mean for Missouri. Obtained from the Missouri Climate Center (MCC).

Figure 4.2. The observed precipitation for December 1889 and March 2012 in the cUSA $\left({ }^{\circ} \mathrm{C}\right)$ compared to the mean for Missouri. Obtained from the Missouri Climate Center (MCC).

Figure 4.3. The surface temperature anomaly maps for A) December 1889, and B) March 2012. The units shown are $\left({ }^{\circ} \mathrm{C}\right)$. Generated by the NOAA/ESRL Physical Sciences Division.

Figure 4.4. The mean $500 \mathrm{mb}$ Geopotential Height (DAM) Maps for A) December 1889, and B) March 2012. The contour interval is 60 meters. Map generated by the NOAA/ESRL Physical Sciences Division.

Figure 4.5. The $500 \mathrm{mb}$ mean Geopotential Height (m) Anomalies for A) December 1889, and B) March 2012. The contour interval is $30 \mathrm{~m}$. Map generated by the NOAA/ESRL Physical Sciences Division.

Figure A.1. January $1979\left(-7.6^{\circ} \mathrm{C}\right) 500 \mathrm{mb}$ averaged chart. A strong meridional flow present through the cUSA area, with a digging trough from the North.

Figure A.2. July $1980\left(+5.1{ }^{\circ} \mathrm{C}\right) 500 \mathrm{mb}$ averaged chart. Heights rose extremely high across Tornado Alley, strongly effecting cUSA region. Persistent zonal flow observed.

Figure A.3. April $1983\left(-3.8^{\circ} \mathrm{C}\right) 500 \mathrm{mb}$ averaged chart. Very polarizing illustration, showing very zonal in the Southern half and meridional in the North. The Central USA region just catches the cooler Northwestern flow.

Figure A.4. December $1983\left(-8.7^{\circ} \mathrm{C}\right) 500 \mathrm{mb}$ averaged chart. A trough is present across the entire USA. Definitely contributed to cooler temperatures and flowing pressure systems across cUSA. 
Figure A.5. March $1984\left(-3.8^{\circ} \mathrm{C}\right) 500 \mathrm{mb}$ averaged chart. A piling ridge over the Pacific Coast and prominent trough throughout the Southern states give the cUSA a consistent Northwesterly flow throughout the month.

Figure A.6. October $1988\left(-3.6^{\circ} \mathrm{C}\right) 500 \mathrm{mb}$ averaged chart. A consistent piling ridge and digging trough contribute to a meridional flow pattern across the cUSA, dropping temperatures.

Figure A.7. December $1989\left(-6.5^{\circ} \mathrm{C}\right) 500 \mathrm{mb}$ averaged chart. A much stronger ridge/trough pairing across the USA no doubt contributes to a much more frigid December.

Figure A.8. August $1992\left(-3.4^{\circ} \mathrm{C}\right) 500 \mathrm{mb}$ averaged chart. Higher heights observed alongside a meridional flow pattern observed across cUSA region.

Figure A.9. September $1998\left(+4.9^{\circ} \mathrm{C}\right) 500 \mathrm{mb}$ averaged chart. High heights and persistent zonal flow observed across cUSA region, with a piling ridge sitting over Nebraska.

Figure A.10. December $2000\left(-7.4^{\circ} \mathrm{C}\right) 500 \mathrm{mb}$ averaged chart. A strong digging trough is located through Missouri and Kentucky, resulting in a definitive meridional flow within the cUSA, and a large spread in height values.

Figure A.11. November $2001\left(+3.7^{\circ} \mathrm{C}\right) 500 \mathrm{mb}$ averaged chart. An overall zonal flow with no cooler airflow from the North leads to an anomalously warm Nov. in the cUSA region.

Figure A.12. August $2004\left(-3.5^{\circ} \mathrm{C}\right) 500 \mathrm{mb}$ averaged chart. This is nearly identical to what is observed in Figure A.8. where higher heights are observed across the cUSA but a slight meridional flow pattern lead to a cooler August.

Figure A.13. January $2006\left(+6.4{ }^{\circ} \mathrm{C}\right) 500 \mathrm{mb}$ averaged chart. Very warm January month for the cUSA, due to a consistent zonal flow pattern and lack of Northern systems.

Figure A.14. March $2007\left(+5.2^{\circ} \mathrm{C}\right) 500 \mathrm{mb}$ averaged chart. Persistent zonal flow across the nation leads to an abrupt end of winter throughout the cUSA region.

Figure A.15. August $2007\left(+3.6^{\circ} \mathrm{C}\right) 500 \mathrm{mb}$ averaged chart. A high sustained height value across the cUSA for the month August and zonal flow patterns result to a extended summer.

Figure A.16. October $2009\left(-3.7^{\circ} \mathrm{C}\right) 500 \mathrm{mb}$ averaged chart. A meridional flow spreads across the nation with a ridge over the Pacific and a trough in Colorado, leading to a lower temperature flow throughout the cUSA. 
Figure A.17. March $2012\left(+9.0^{\circ} \mathrm{C}\right) 500 \mathrm{mb}$ averaged chart. As elaborated upon in Chapter 4 and Figure 4.4B, this is the hottest March on record due to a strong anomalous Westerly flow and higher height values.

Figure A.18. July $2012\left(+4.2^{\circ} \mathrm{C}\right) 500 \mathrm{mb}$ averaged chart. A more severe case then Figure A.2., as this summer month set blazing records for not only the cUSA region, but across the entire nation. The country was locked underneath an absurdly high zonal flow region.

Figure A.19. November $2015\left(+4.2^{\circ} \mathrm{C}\right) 500 \mathrm{mb}$ averaged chart. A digging trough that formed along the Californian Coast made way for a smooth zonal airflow to affect the cUSA region most of the month.

Figure A.20. March $2016\left(+4.4^{\circ} \mathrm{C}\right) 500 \mathrm{mb}$ averaged chart. The most recent warm March, the cUSA was locked under a mild zonal flow, raising temperatures throughout the month. 


\section{LIST OF TABLES}

Table 2.1. The criterion used of each season for the cUSA and swRUS months.

Table 2.2. Center for Ocean-Atmospheric Prediction Studies Japan Meteorological Agency El Niño Southern Oscillation Index, 1889 to present.

Table 2.3. 1900 to present time index for the Pacific Decadal Oscillation. 1944 to present time index for the North Atlantic Oscillation. PDO modes are high (positive) and low (negative). NAO modes define as a positive (negative) value, representing a more meridional (zonal) flow over that region.

Table 3.1. Results for the cUSA and swRUS. Shown are raw counts and normalized monthly extreme events with respect to values in Table ( $\mathrm{T}$ is total, $\mathrm{W}$ is warm, and $\mathrm{C}$ is cold).

Table 3.2. The occurrence of extreme temperature and precipitation months stratified by ENSO phase and season.

Table 3.3. The ratio of extreme warm to cold (wet to dry) months with respect to the phase of PDO and NAO, in cUSA and swRUS.

Table 3.4. The 96 listed central USA (cUSA) temperature anomaly events.

Table 3.5. The 45 listed southwest RUS (swRUS) temperature anomaly events. 


\begin{abstract}
There has been a lot of focus on the occurrence of extreme weather events and their connection to climate change and variability. Much of this previous work has been related to individual events rather than for mean monthly conditions. This study examined the occurrence of extreme conditions in the monthly temperature and precipitation, and some correlations, for two geographically disparate regions of the Northern Hemisphere. These regions are the central USA (cUSA), and the southwest region of Russia (swRUS). For this research, an extreme temperature event was defined as a month that was three seasonal standard deviations from the period mean. Since precipitation is not normally distributed, the three (two) wettest and driest events of every month were chosen for the cUSA (swRUS) region in order to provide for a data set that was of similar size to the temperature data set for each region. The results demonstrate that in cUSA, there was preference for the occurrence of warm anomalies during periods of mean regional temperature increase and vice versa. For swRUS, there was a preference for the occurrence of cold anomalies early in the data set, and warm anomalies in the later part, although this period is one of steadily increasing mean temperatures for the region. There was a strong association at both locations between extreme months and the phase of the El Niño-Southern Oscillation (ENSO). In both regions, cold monthly anomalies were associated with persistent and strong upstream blocking events. Finally, two case studies are examined for the cUSA region.
\end{abstract}




\section{CHAPTER 1. INTRODUCTION}

In recent years, there has been increased attention to the occurrence of extreme weather in the research and general community, especially within the context of climate change (e.g., IPCC, 2014: Topic 1.4). However, recent research has demonstrated that even with an increase in global temperatures, important interannual and interdecadal variability can still impart a strong signal on local or regional climate (e.g., Kylyshtorin and Lyubushin, 2007; Swanson, 2007; Johnstone and Mantua, 2014). Johnstone and Mantua (2014) show that interdecadal variability related to the Pacific Decadal Oscillation (PDO) contributed strongly to the climate record of the Northwest USA since 1900. Also, many researchers have examined the interannual and interdecadal variability of temperature and other variables regionally (e.g., Gershonov and Barnett, 1998; Birk et al 2010; Lupo et al 2012a).

Studies of the interannual or interdecadal variability of the occurrence of extreme events is not new and has typically been accomplished using phenomenological events such as hurricanes (e.g., Zuki and Lupo, 2008a; Lupo, 2011), tornadoes (e.g., Marzban and Schaefer, 2001; Akyuz et al. 2004), or blocking events (e.g., Hakkinen et al. 2011; Lupo et al. 2012b; Mokhov et al. 2012; Abraham et al. 2012). Many have examined the occurrence of extreme temperatures and how their occurrence might change in the 21st century (e.g., Birk et al. 2010). Other studies have attributed the recent occurrence of extreme events to climate change (e.g., IPCC, 2013: Topic B.1; NAS, 2016). However, very few have examined the occurrence of extreme months. 
The goal of this thesis is to examine the occurrence of extremely warm and cold (wet and dry) months occurring in two continental regions: Columbia, MO (cUSA) and southwest Russia (swRUS). A case study over two incredibly anomalous warm months in the cUSA region (December 1889 and March 2012) was conducted to examine how atmospheric circulation during extreme months compared to those during normal conditions. This study is also unique since many papers have studied the occurrence of extreme cold months over North America, which have been related to Pacific Region ridging or blocking (e.g., Quiroz, 1984; Jensen, 2015). To my knowledge, there is no comparable study for either region of extreme warm months.

This thesis is structured across six chapters. Chapter two will present the data and analysis methods used, Chapter three will examine the climatological results, and the interannual and interdecadal variability, and Chapter four will discuss atmospheric patterns of the two extreme warm months observed in the case study. Chapter five will discuss how this statistical analysis correlates to other studies and the kinds of trends that were identified, while Chapter six provides a summary of the thesis and general conclusions.

\subsection{Objectives}

With intense meteorological patterns in the cUSA and swRUS, showing a correlation to extreme temperature and precipitation (Swanson, 2007; Johnstone and Mantua, 2014), those extreme events also correlate to ENSO, PDO, and NAO variability. The hypothesis stands that extreme temperature and precipitation anomalies will also 
correspond to interannual and interdecadal variability, along with persistent blocking patterns. Thus, the objectives of this research are as follows:

1. Determine if the variability of temperature and precipitation extremes, within the cUSA and swRUS regions, exists in relationship to ENSO, PDO and NAO variability.

2. Determine what relationship that blocking events have with temperature anomalies.

\subsection{Statement of Thesis}

The intent of this research is to advance of knowledge related to the occurrence of extreme weather months. Specifically, this study will describe:

1. ENSO, PDO and NAO impacts for both cUSA and swRUS regions.

2. Blocking patterns being enhanced or suppressed in connection with temperature events.

3. The implications for long-range forecasting. 


\section{CHAPTER 2. DATA AND METHODOLOGY}

\subsection{Data Sources}

The study regions include the Columbia region (cUSA), which is defined as central and eastern Missouri (Figure 2.1), and the Belgorod Oblast and surrounding regions (swRUS; Figure 2.2). In this study, the units for surface temperature are uniformly converted to Celsius (Lupo et al. 2003). Data for cUSA were obtained from the Missouri Climate Center (MCC) located at the University of Missouri in Columbia Missouri (NOAA/NCEI). These records date back to September of 1889, providing a 128-year data set through 2016. The data for swRUS were surface temperature and precipitation data for the Belgorod Oblast obtained from the All Russia Research Institute of Hydrometeorological Information-World Data Centre (RIHMI-WDC http://meteo.ru/) from 1944 to 2016. Birk et al. 2010 and Lebedeva et al. (2015) demonstrate that these data are generally representative of their regions as a whole.

The blocking archives (http://weather.missouri.edu/gcc) at the University of Missouri were used to compile the character of blocking associated with extreme months, with records dating back to 1968 (July $1^{\text {st }}$ ) from present day. Additional blocking records for events prior to 1968 were acquired from NOAA's $-20^{\text {th }}$ Century Reanalysis; particularly for the December of 1889 case study. The Twentieth Century Reanalysis Project generated a six-hourly, four-dimensional global atmospheric dataset spanning 1851-2016 to place current atmospheric circulation patterns into a historical perspective. This is possible from the use of a state-of-the-art data assimilation system and surface 
Figure 2.1. Map of Columbia in the cUSA study region. Studies demonstrate Columbia records are wholly representative of entire state of Missouri (cUSA) east of the black line (Birk and Lebedeva). Provided from the United States Department of Commerce Weather Bureau and presents the Climatological divisions from 1957 to present.

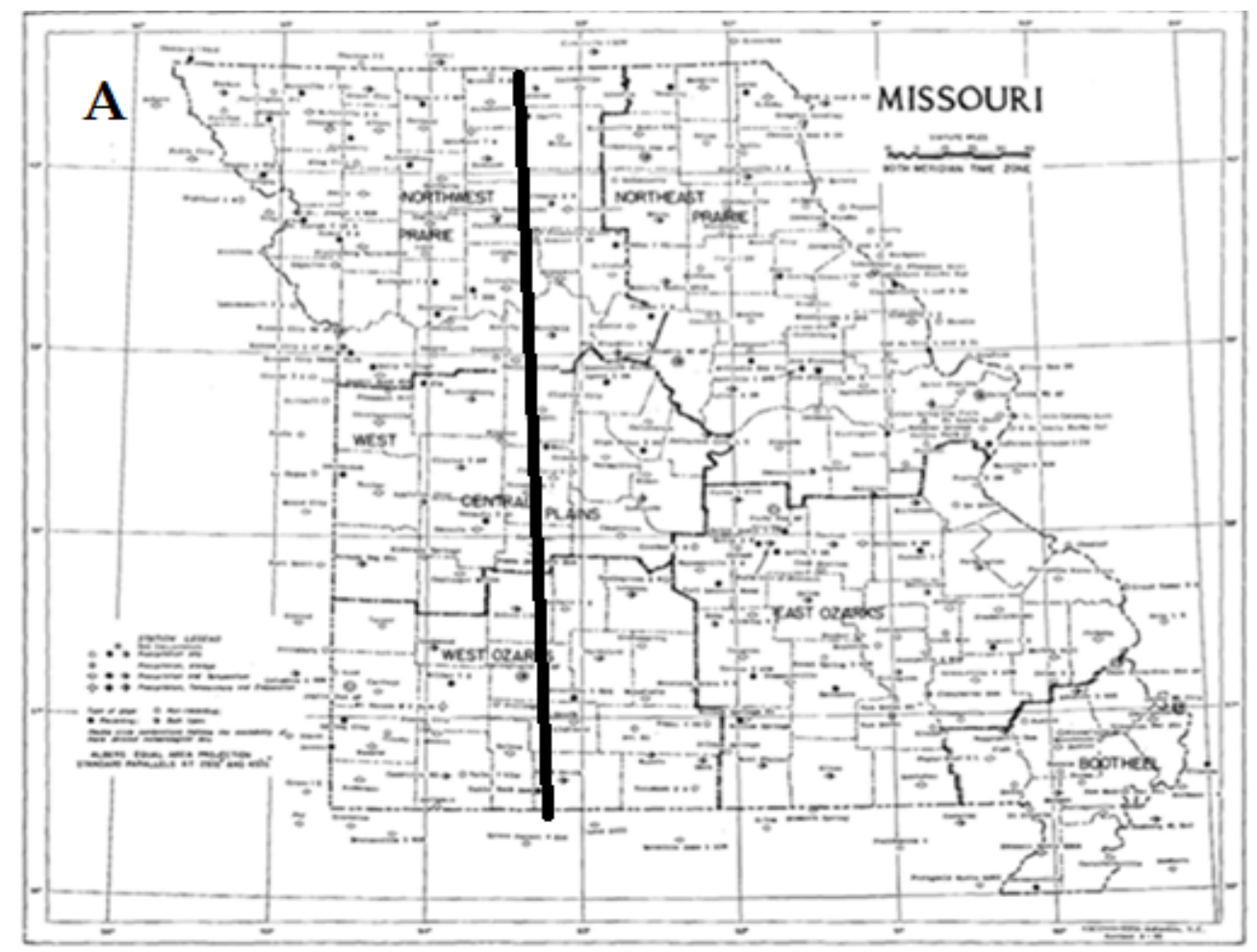

pressure observations. The dataset provided the first estimates of atmospheric circulation spanning back to 1851. The National Centers for Environmental Prediction / National Center for Atmospheric Research (NCEP/NCAR) reanalysis and $20^{\text {th }}$ century reanalysis products are gridded at $2.5^{\circ} \times 2.5^{\circ}$ resolution. The $500 \mathrm{mb}$ geopotential height fields $(\mathrm{m})$ from December of 1889 was primarily recovered, using this source. 
Figure 2.2. Map of swRUS Belgorod Oblast study region. Shows the relative location within Russia, provided by Bradley University.
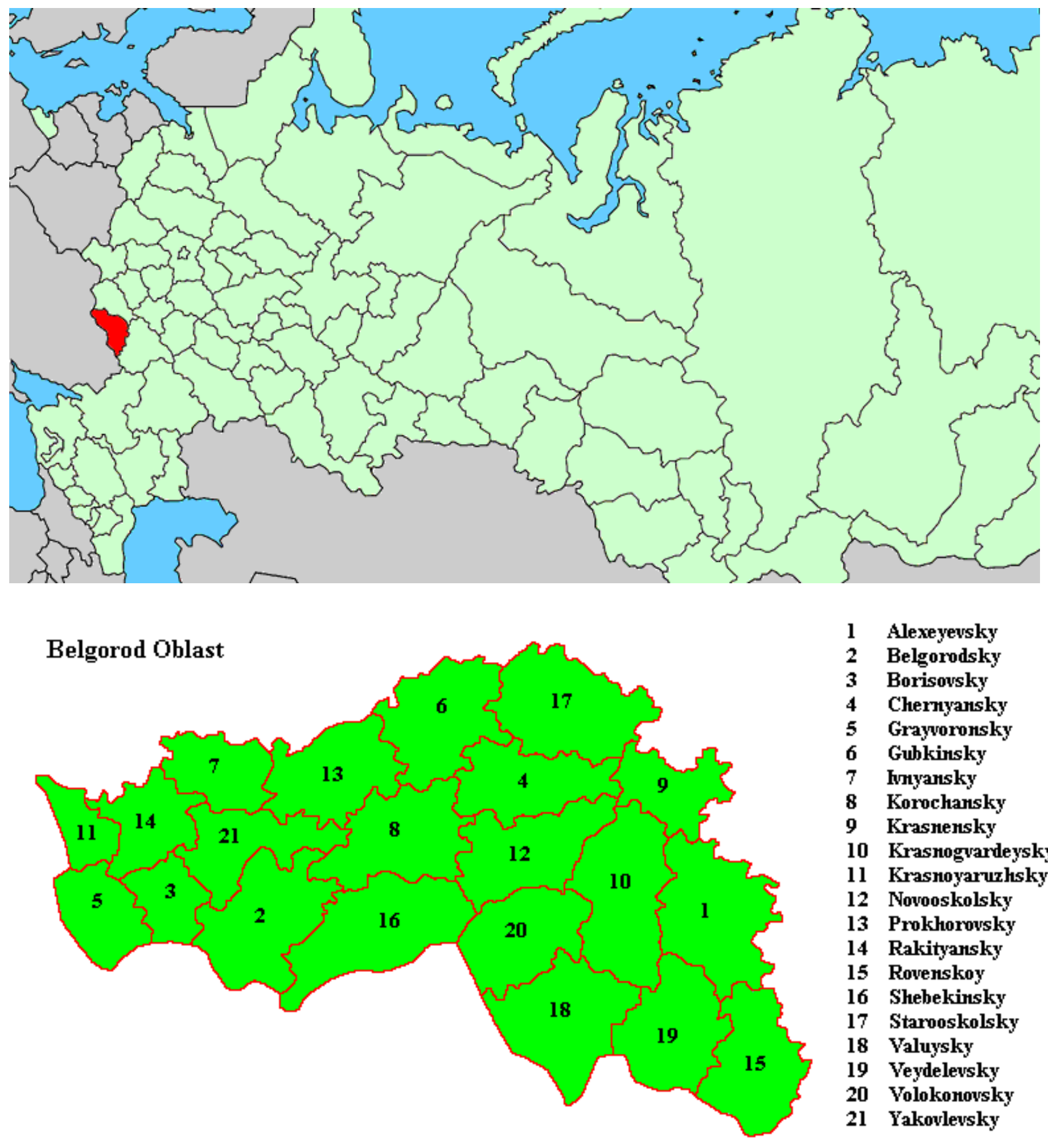

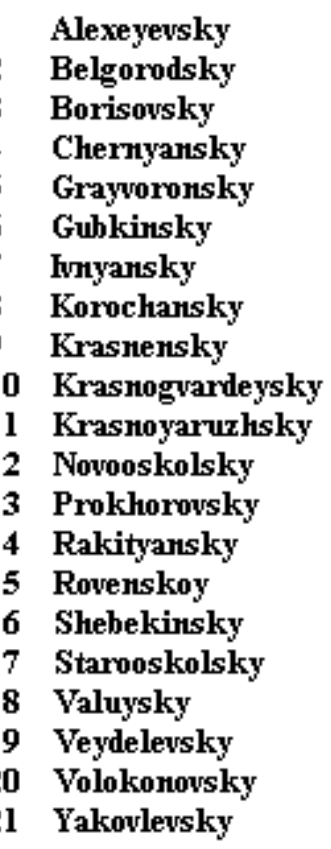


Table 2.1. The temperature criterion used for each season in the cUSA and swRUS months.

\begin{tabular}{|c|c|}
\hline Season & Three Seasonal $^{\boldsymbol{\sigma}}\left(\mathbf{c U S A}^{\mathbf{}}{ }^{\mathbf{C}} / \mathbf{s w}_{\text {RUS }}{ }^{\mathbf{}} \mathbf{C}\right)$ \\
\hline Winter - DJF & $5.7 / 7.8$ \\
\hline Spring - MAM & $3.7 / 5.6$ \\
\hline Summer - JJA & $3.6 / 4.4$ \\
\hline Fall - SON & $3.5 / 4.4$ \\
\hline
\end{tabular}

\subsection{Methods}

To be considered an extreme event in the cUSA and swRUS, this study specified that the monthly mean temperature for the region of study had to be at least three seasonal standard deviations $(3 \sigma)$ above or below that months mean, derived from the entire data set for that particular month. The three standard deviation threshold was based on the seasonal mean in order that the sample size produced was large enough for statistical analysis. The $3 \sigma$ thresholds used in this study are presented in Table 2.1. There were 1536 total months in the cUSA and 876 in swRUS. The three seasonal criterion used here gave a sample size of 96 and 45 months $(6 \%$ and $5 \%$ of all) in the cUSA and swRUS, without obtaining so many months that the meaning of an extreme event would be lost but enough to conduct a statistical analysis. Since precipitation is not normally distributed (Lupo et al. 2003), only the three (two) wettest and driest of each 12 months were selected as precipitation events. This provides the study with approximately as many months (72 and 48 respectively) for the precipitation analysis in each region as there were for the temperature data. 
Table 2.2. Center for Ocean-Atmospheric Prediction Studies (COAPS) Japan Meteorological Agency El Niño Southern Oscillation Index, 1889 to present. Modes are El Niño (EL), La Niña (LA) and Neutral (NEU).

\begin{tabular}{|c|c|c|}
\hline El Niño & Neutral & La Niña \\
\hline 1896 & $1890-1891$ & 1889 \\
\hline 1899 & 1894-1895 & $1892-1893$ \\
\hline 1902 & $1897-1898$ & 1903 \\
\hline 1904-1905 & $1900-1901$ & 1906 \\
\hline 1911 & 1907 & $1908-1910$ \\
\hline 1913 & 1912 & 1916 \\
\hline 1918 & 1914-1915 & 1922 \\
\hline 1925 & 1917 & 1924 \\
\hline $1929-1930$ & 1919-1921 & 1938 \\
\hline 1940 & 1923 & 1942 \\
\hline 1951 & $1926-1928$ & 1944 \\
\hline 1957 & 1931-1937 & 1949 \\
\hline 1963 & 1939 & 1954-1956 \\
\hline 1965 & 1941 & 1964 \\
\hline 1969 & 1943 & 1967 \\
\hline 1972 & $1945-1948$ & 1970-1971 \\
\hline 1976 & 1950 & 1973-1975 \\
\hline 1982 & 1952 & 1988 \\
\hline 1986-1987 & 1953 & 1998-1999 \\
\hline 1991 & $1958-1962$ & 2007 \\
\hline 1997 & 1966 & 2010 \\
\hline 2002 & 1968 & 2016 \\
\hline 2006 & 1977-1981 & \\
\hline 2009 & 1983-1985 & \\
\hline \multirow[t]{6}{*}{$2014-2015$} & 1989-1990 & \\
\hline & $1992-1996$ & \\
\hline & $2000-2001$ & \\
\hline & $2003-2005$ & \\
\hline & 2008 & \\
\hline & $2011-2013$ & \\
\hline
\end{tabular}


Figure 2.3. El Niño Southern Oscillation Index time series 1950 - present. Supplied from the NOAA Physical Sciences Division - located at the University of Colorado.

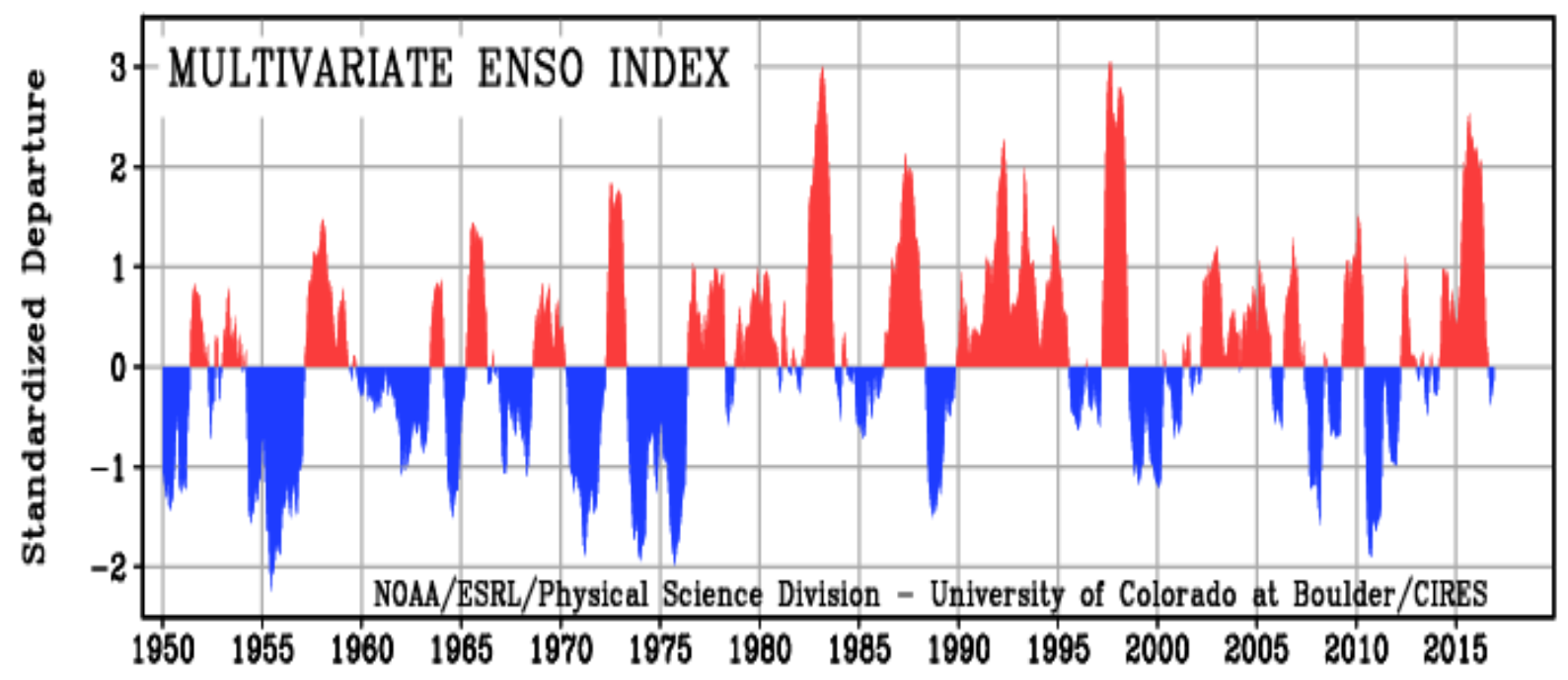

Table 2.3. 1900 to present time index for the Pacific Decadal Oscillation. 1944 to present time index for the North Atlantic Oscillation. PDO modes are high (positive) and low (negative). NAO modes define as a positive (negative) value, representing a more meridional (zonal) flow over that region.

\begin{tabular}{|c|c|}
\hline Year Range & Mode \\
\hline $1900-1924$ & -PDO \\
\hline $1925-1946$ & + PDO \\
\hline $1947-1976$ & $-\mathrm{PDO}$ \\
\hline $1977-1998$ & $+\mathrm{PDO}$ \\
\hline $1999-2014$ & $-\mathrm{PDO}$ \\
\hline $2015-$ present & $+\mathrm{PDO}$ \\
\hline $1944-1950$ & $+\mathrm{NAO}$ \\
\hline $1951-1973$ & $-\mathrm{NAO}$ \\
\hline $1974-2008$ & $+\mathrm{NAO}$ \\
\hline $2009-$ present & $-\mathrm{NAO}$ \\
\hline
\end{tabular}


The definition for ENSO was based on that of the Japanese Meteorological Association (COAPS - JMA). The list of years and their associated ENSO phase can be found at (http://coaps.fsu.edu/jma) via Table 2.2. This definition has been used in many published studies (see Birk et al. 2010 and references therein). The year(s) listed in each category (Cold Phase, Neutral Phase, Warm Phase) correspond to the first three months of the ENSO year namely October, November, and December. For example, the ENSO year 1981 begins October $1^{\text {st }}, 1981$ and ends September $30^{\text {th }}, 1982$. The rocky fluctuation patterns of the ENSO phases are illustrated in Figure 2.3. The Pacific Decadal Oscillation is defined as a warm or cool phase based on the relative comparison of the predominant sea surface temperature (SST) pattern in the Western versus Eastern Pacific region and as defined in Birk et al. (2010). The periods are shown in Table 2.3 and are defined by the Joint Institute for the Study of the Atmosphere and Ocean (JISAO). In swRUS, the periods associations with the North Atlantic Oscillation (NAO) were examined as well (Table 2.3) and defined by the GCC (http://weather.missouri.edu/gcc). The NAO index is defined as a positive or negative phase and is based on the surface sealevel pressure difference between the Subtropical (Azores) High and the Subpolar Icelandic Low (see NOAA definition https://ncdc.noaa.gov/teleconnections/nao/). The positive (negative) phase exemplifies below (above) normal height and pressure observations across the high latitudes of the North Atlantic, eastern United States and Western Europe. 


\section{CHAPTER 3. STATISTICS}

\subsection{Climatological Analysis}

The climatological analysis found 96 and 45 extreme temperature months for cUSA and swRUS, respectively. Table 3.1 shows the seasonal breakdown of the normalized extreme monthly temperature anomalies for cUSA and swRUS. Overall, there were slightly more warm (cold) anomalies for the cUSA (swRUS), but the difference was minor enough, to be close to what would be expected if occurrence of extreme months in the 128 (73) year period were random occurrent. These 96 events are listed in Table 3.4. Comparing both regions demonstrates that in the cUSA an extremely warm or cold month occurred in three of every four years, but approximately six times during every decade in the swRUS region. The more frequent temperature extreme occurrence in the cUSA is presumed to be due to geographical differences between the two regions, paired with the existence of the Mediterranean Jet Stream.

Examining individual seasons for both regions demonstrates that while the raw anomalies were largest in the winter months (not shown), the extreme months were more frequent during the transition seasons of spring and fall (Table 3.1 and Table 3.4). There were some trends found throughout the warm and cool seasons in both regions. In the winter season for the cUSA, cold anomalies occurred three times as often as warm anomalies, however, during the summer season, there was nearly double the amount of warm extreme months (13) than cool extreme months. This dominance of cold (warm) anomalies in the cold (warm) season was particularly true for swRUS as well. 
Table 3.1. Results for the cUSA and swRUS. Shown are raw counts and normalized monthly extreme events with respect to values in Table ( $\mathrm{T}$ is total, $\mathrm{W}$ is warm, and $\mathrm{C}$ is cold). Extreme $\mathrm{W} / \mathrm{C}$ rows list the most extreme months deviation/3 $\sigma$ ratio by (month/year).

\begin{tabular}{|c|c|c|c|c|c|}
\hline Category & Winter & Spring & Summer & Fall & Total \\
\hline \multicolumn{6}{|c|}{ cUSA } \\
\hline Occurrence & $20 \mathrm{~T} 5 \mathrm{~W} 15 \mathrm{C}$ & $\begin{array}{c}29 \mathrm{~T} 16 \mathrm{~W} \\
13 \mathrm{C}\end{array}$ & $20 \mathrm{~T} 13 \mathrm{~W} 7 \mathrm{C}$ & $27 \mathrm{~T} 16 \mathrm{~W} 11 \mathrm{C}$ & $96 \mathrm{~T} 50 \mathrm{~W} 46 \mathrm{C}$ \\
\hline $\begin{array}{l}\text { Percent of } \\
\text { All Years }\end{array}$ & $16 \mathrm{~T} 4 \mathrm{~W} 12 \mathrm{C}$ & $\begin{array}{c}22 \mathrm{~T} 12 \mathrm{~W} \\
10 \mathrm{C}\end{array}$ & $16 \mathrm{~T} 10 \mathrm{~W} 6 \mathrm{C}$ & $20 \mathrm{~T} 11 \mathrm{~W} 9 \mathrm{C}$ & $74 \mathrm{~T} 37 \mathrm{~W} 37 \mathrm{C}$ \\
\hline Extreme W & $1.6-12 / 1889$ & $2.5-3 / 2012$ & $1.4-7 / 1980$ & $1.8-10 / 1963$ & $2.5-3 / 2012$ \\
\hline Extreme C & $1.6-1 / 1977$ & $1.8-3 / 1906$ & $1.3-8 / 1915$ & $1.6-10 / 1925$ & $1.8-3 / 1906$ \\
\hline \multicolumn{6}{|c|}{ swRUS } \\
\hline Occurrence & 9T $1 \mathrm{~W} 8 \mathrm{C}$ & $13 \mathrm{~T} 9 \mathrm{~W} 4 \mathrm{C}$ & 7T 7W 0C & $16 \mathrm{~T} 5 \mathrm{~W} 11 \mathrm{C}$ & $45 \mathrm{~T} 22 \mathrm{~W} 23 \mathrm{C}$ \\
\hline $\begin{array}{l}\text { Percent of } \\
\text { All Years }\end{array}$ & $12 \mathrm{~T} 1 \mathrm{~W} 11 \mathrm{C}$ & $18 \mathrm{~T} 12 \mathrm{~W} 6 \mathrm{C}$ & $10 \mathrm{~T} 10 \mathrm{~W} 0 \mathrm{C}$ & $22 \mathrm{~T} 7 \mathrm{~W} 15 \mathrm{C}$ & $63 \mathrm{~T} 31 \mathrm{~W} 32 \mathrm{C}$ \\
\hline Extreme W & $1.0-2 / 2002$ & $1.1-3 / 2007$ & $1.5-8 / 2010$ & $1.6-11 / 2010$ & $1.6-11 / 2010$ \\
\hline Extreme $\mathrm{C}$ & $1.4-1 / 1950$ & $1.4-3 / 1952$ & $\mathrm{~N} / \mathrm{A}$ & $1.9-11 / 1993$ & $1.9-11 / 1993$ \\
\hline
\end{tabular}

There was little overall temperature trends during the 128-year period (slightly positive, not statistically significant) in the Columbia region using the running 30 -year means which are typically used to define climatology. The winter season temperatures showed the largest increase (about $0.56{ }^{\circ} \mathrm{C}$ ) while the spring showed only a slight increase in temperature. Summer showed no change in temperature, while the fall season temperatures decreased about $0.4{ }^{\circ} \mathrm{C}$ over the period of record. Within the swRUS Region, temperature increased $1.53{ }^{\circ} \mathrm{C}$ for the annual value over the 73 -year period, a result statistically significant at $95 \%$ using an F-test. During the winter and spring 
seasons, the increase was more than $2{ }^{\circ} \mathrm{C}$, while during the summer and fall seasons, the increase was smaller, around $0.7{ }^{\circ} \mathrm{C}$ and $1{ }^{\circ} \mathrm{C}$, respectively. Since the swRUS region showed constant increases in temperature since 1980, it is no surprise that 17 of 22 (4 of 23) warm (cold) anomalies occurred after 1990. The cUSA temperatures have varied over the 128-year period annually (not shown). Thus, it is instructive to examine the occurrence of these anomalies with respect to interannual and interdecadal internal climate variability. Precipitation is not examined in this section since each month/season produced a set number of wet and dry anomalies as per the method described in section 2.2 .

\subsection{Interannual and Interdecadal Variability}

Occurrences stratified by ENSO phase were normalized and represented as a mean annual occurrence since ENSO neutral years account for a majority of the periods of study for both regions. In the cUSA, there were 68 neutral years, and 31 (29) La Niña (El Niño events), while in swRUS, these counts were 38, and 18 (17) years, respectively. Table 3.2 shows the occurrences of extreme months stratified by ENSO mode in both regions. Extremely warm or cold monthly temperatures in cUSA are most likely during the neutral and El Niño phases. In contrast, extreme temperature months were likely to occur only during one in every two La Niña years, with a $4 \%$ chance of any given La Niña month being extreme. The probability of extreme months during El Niño or neutral years is $6 \%$. In swRUS, the occurrence of extreme monthly temperatures was more likely in both La Niña and El Niño phases (about 6\% probability) as opposed to neutral 
Table 3.2. The occurrence of extreme temperature and precipitation months stratified by ENSO phase and season expressed as an occurrence per year for each individual phase for the total numbers in Table 2.2. These will appear as T/P in each cell.

\begin{tabular}{|l|l|l|l|l|l|}
\hline Phase & Winter & Spring & Summer & Fall & Total \\
\hline cUSA & \multicolumn{5}{|l|}{} \\
\hline E1 Niño & $0.19 / 0.19$ & $0.27 / 0.07$ & $0.13 / 0.07$ & $0.30 / 0.07$ & $0.80 / 0.41$ \\
\hline Neutral & $0.19 / 0.19$ & $0.24 / 0.16$ & $0.21 / 0.19$ & $0.16 / 0.18$ & $0.79 / 0.65$ \\
\hline La Niña & $0.07 / 0.03$ & $0.13 / 0.20$ & $0.00 / 0.10$ & $0.17 / 0.13$ & $0.50 / 0.47$ \\
\hline & & & & \\
\hline \multicolumn{7}{|l|}{ swRUS } & $0.13 / 0.20$ & $0.27 / 0.13$ & $0.13 / 0.20$ & $0.20 / 0.27$ & $0.73 / 0.80$ \\
\hline E1 Niño & $0.10 / 0.15$ & $0.15 / 0.22$ & $0.07 / 0.20$ & $0.20 / 0.20$ & $0.51 / 0.78$ \\
\hline Neutral & 0.19 & $0.13 / 0.06$ & $0.31 / 0.00$ & $0.81 / 0.31$ \\
\hline La Niña & $0.19 / 0.19$ & $0.19 / 0.06$ & $0.13 / 0$ &
\end{tabular}

months (about 4\%). There was some variation across seasons in swRUS in that during the fall season, La Niña was more likely to have an extreme temperature occurrence. This table also demonstrates that the transition seasons were most likely to have the occurrence of extreme warm or cold months in both regions. In swRUS, the probability of extreme warm or cold months was similar to that of cUSA overall. For neutral (El Niño) extreme months in the cUSA, there were more warm (cold) anomalies. In the cUSA summer, neutral months accounted for $80 \%$ of all summer extremes, and this was the highest percentage amongst any of the seasons for that region.

For precipitation in both regions, the distributions were different from the temperature. In the cUSA, neutral years produced the most extreme wet or dry months, while in swRUS it was El Niño and neutral years producing the most extremes. In the cUSA the neutral years dominated the summer and fall season, but during the winter and 
Table 3.3. The ratio of extreme warm to cold (wet to dry) months with respect to the phase of the PDO and NAO, in cUSA and swRUS, respectively. A value greater than 1 indicates more warm or dry months, and vice versa.

\begin{tabular}{|c|c|c|c|}
\hline & & Temperature & Precipitation \\
\hline \multirow{2}{*}{ cUSA } & & & \\
\cline { 2 - 4 } & PDO+ & 1.13 & 1.58 \\
\hline \multirow{2}{*}{ swRUS } & PDO- & 0.93 & 0.63 \\
\cline { 2 - 4 } & NAO+ & 1.40 & \\
\cline { 2 - 4 } & NAO- & 0.62 & 0.80 \\
\hline
\end{tabular}

spring shared predominance with either El Niño (winter) or La Niña (spring). For swRUS, La Niña years were as common as the other phases during the winter season only.

An examination of the occurrence of extreme months in association with the positive and negative PDO phases, showed a weak tendency toward the occurrence of extreme warm (cold) temperature anomalies with the warm (cold) phase of the PDO in the cUSA (Table 3.3). In swRUS, there was a greater tendency for extreme warm months during the positive NAO, representing a more meridional flow for the region as opposed to the negative phase that is more zonal (Table 3.3). This may be due to the variations in the occurrence of blocking, and this will be investigated in the next section. For the precipitation occurrences, there was an association for the occurrence of wet (dry) extremes during the positive (negative) phase of the PDO in the cUSA. In the swRUS 
region, there was only a weak, non-statistically significant variation in wet versus dry months during the NAO.

\subsection{Temperature Analysis of cUSA and swRUS}

Table 3.4 lists the 96-cUSA events (months) and the temperature difference, relative to each respective year and month. It displays how much higher of a temperature difference exists within the winter (December, January, February) months compared to the other three seasons. With the raw anomaly shown to be the largest in the winter season (see in Table 2.1), Table 3.4 also illustrates the higher rate of the larger magnitude and more frequent, normalized anomalies that were observed in the transitional (fall and spring) seasons. The spring (March, April, May) months experienced 29 events, and the fall (September, October, November) months endured 27 temperature events. That tallied to 58 percent (56/96) of the total anomalies observed. Summer, and the winter months were the least frequent occurred temperature anomaly seasons, composing of 42 percent (40/96) of all accounted anomalies. This pattern was also notable in the swRUS region.

The 45 temperature anomalies (months) that occurred in swRUS are similarly summarized in Table 3.5. Warm (cold) anomalies dominated the warm (cool) seasons; as all seven observed summer months (June, July, August) were warm events, while only one of winters nine events were warm (February 2002). Compared to Table 3.4, there were significantly less anomalous months throughout the swRUS region than in cUSA, relative to each regions respective sample size. As alluded in Chapter 3.1, this is presumed to be due to regional and geographical differences within the North 
Table 3.4. The 96 central USA (cUSA) temperature anomaly events listed in chronological order per month from September 1889 to December 2016. Temperature deviations from monthly mean listed next to events, in degrees Celsius $\left({ }^{\circ} \mathrm{C}\right)$.

\begin{tabular}{|c|c|c|c|c|c|c|c|c|c|c|c|}
\hline Jan. & Feb. & Mar. & April & May & June & July & Aug. & Sept. & Oct. & Nov. & Dec. \\
\hline $\begin{array}{l}1912 \\
(-6.7)\end{array}$ & $\begin{array}{l}1899 \\
(-7.4)\end{array}$ & $\begin{array}{l}1890 \\
(-3.7)\end{array}$ & $\begin{array}{l}1896 \\
(+4.8)\end{array}$ & $\begin{array}{l}1896 \\
(+3.8)\end{array}$ & $\begin{array}{l}1903 \\
(-3.8)\end{array}$ & $\begin{array}{l}1901 \\
(+4.1)\end{array}$ & $\begin{array}{l}1913 \\
(+3.6)\end{array}$ & $\begin{array}{l}1897 \\
(+3.9)\end{array}$ & $\begin{array}{l}1897 \\
(+3.7)\end{array}$ & $\begin{array}{l}1902 \\
(+3.6)\end{array}$ & $\begin{array}{r}1889 \\
(+8.9)\end{array}$ \\
\hline $\begin{array}{l}1918 \\
(-7.9)\end{array}$ & $\begin{array}{l}1902 \\
(-6.1)\end{array}$ & $\begin{array}{l}1906 \\
(-6.5)\end{array}$ & $\begin{array}{l}1904 \\
(-3.9)\end{array}$ & $\begin{array}{l}1924 \\
(-3.8)\end{array}$ & $\begin{array}{l}1928 \\
(-3.8)\end{array}$ & $\begin{array}{r}1934 \\
(+4.9)\end{array}$ & $\begin{array}{l}1915 \\
(-4.6)\end{array}$ & $\begin{array}{l}1918 \\
(-4.1)\end{array}$ & $\begin{array}{l}1917 \\
(-4.9)\end{array}$ & $\begin{array}{r}1909 \\
(+4.7)\end{array}$ & $\begin{array}{c}1909 \\
(-5.8)\end{array}$ \\
\hline $\begin{array}{l}1933 \\
(+7.0)\end{array}$ & $\begin{array}{l}1905 \\
(-7.6)\end{array}$ & $\begin{array}{l}1907 \\
(+4.5)\end{array}$ & $\begin{array}{l}1907 \\
(-4.3)\end{array}$ & $\begin{array}{l}1962 \\
(+4.7)\end{array}$ & $\begin{array}{l}1934 \\
(+3.8)\end{array}$ & $\begin{array}{r}1936 \\
(+4.9)\end{array}$ & $\begin{array}{l}1927 \\
(-3.6)\end{array}$ & $\begin{array}{l}1931 \\
(+3.6)\end{array}$ & $\begin{array}{l}1925 \\
(-5.7)\end{array}$ & $\begin{array}{l}1911 \\
(-3.5)\end{array}$ & $\begin{array}{c}1931 \\
(+5.7)\end{array}$ \\
\hline $\begin{array}{l}1940 \\
(-8.7)\end{array}$ & $\begin{array}{r}1930 \\
(+6.2)\end{array}$ & $\begin{array}{r}1910 \\
(+6.8)\end{array}$ & $\begin{array}{l}1915 \\
(+3.9)\end{array}$ & & $\begin{array}{r}1952 \\
(+3.9)\end{array}$ & $\begin{array}{l}1954 \\
(+4.2)\end{array}$ & $\begin{array}{r}1936 \\
(+4.8)\end{array}$ & $\begin{array}{r}1939 \\
(+3.8)\end{array}$ & $\begin{array}{r}1938 \\
(+4.3)\end{array}$ & $\begin{array}{r}1913 \\
(+4.2)\end{array}$ & $\begin{array}{l}1963 \\
(-6.2)\end{array}$ \\
\hline $\begin{array}{l}1977 \\
(-8.8)\end{array}$ & $\begin{array}{l}1936 \\
(-6.5)\end{array}$ & $\begin{array}{l}1912 \\
(-5.6)\end{array}$ & $\begin{array}{l}1926 \\
(-3.7)\end{array}$ & & $\begin{array}{l}1953 \\
(+3.8)\end{array}$ & $\begin{array}{r}1980 \\
(+5.1)\end{array}$ & $\begin{array}{l}1947 \\
(+4.8)\end{array}$ & $\begin{array}{l}1974 \\
(-4.7)\end{array}$ & $\begin{array}{l}1947 \\
(+4.9)\end{array}$ & $\begin{array}{l}1931 \\
(+4.8)\end{array}$ & $\begin{array}{l}1983 \\
(-8.7)\end{array}$ \\
\hline $\begin{array}{l}1979 \\
(-7.6)\end{array}$ & $\begin{array}{l}1978 \\
(-6.4)\end{array}$ & $\begin{array}{l}1915 \\
(-4.7)\end{array}$ & $\begin{array}{l}1955 \\
(+3.9)\end{array}$ & & & $\begin{array}{l}2012 \\
(+4.2)\end{array}$ & $\begin{array}{l}1950 \\
(-3.6)\end{array}$ & $\begin{array}{l}1998 \\
(+4.9)\end{array}$ & $\begin{array}{l}1956 \\
(+3.8)\end{array}$ & $\begin{array}{l}1950 \\
(-3.8)\end{array}$ & $\begin{array}{l}1989 \\
(-6.5)\end{array}$ \\
\hline \multirow[t]{4}{*}{$\begin{array}{l}2006 \\
(+6.4)\end{array}$} & & $\begin{array}{l}1918 \\
(+4.1)\end{array}$ & $\begin{array}{l}1983 \\
(-3.8)\end{array}$ & & & & $\begin{array}{l}1992 \\
(-3.4)\end{array}$ & & $\begin{array}{l}1963 \\
(+6.3)\end{array}$ & $\begin{array}{l}1959 \\
(-3.8)\end{array}$ & $\begin{array}{l}2000 \\
(-7.4)\end{array}$ \\
\hline & & $\begin{array}{l}1921 \\
(+4.7)\end{array}$ & & & & & $\begin{array}{l}2004 \\
(-3.5)\end{array}$ & & $\begin{array}{l}1976 \\
(-4.2)\end{array}$ & $\begin{array}{l}1976 \\
(-5.2)\end{array}$ & \\
\hline & & $\begin{array}{c}1935 \\
(+3.7)\end{array}$ & & & & & $\begin{array}{l}2007 \\
(+3.6)\end{array}$ & & $\begin{array}{l}1988 \\
(-3.6)\end{array}$ & $\begin{array}{l}2001 \\
(+3.7)\end{array}$ & \\
\hline & & $\begin{array}{l}1938 \\
(+5.2)\end{array}$ & & & & & & & $\begin{array}{l}2009 \\
(-3.7)\end{array}$ & $\begin{array}{r}2015 \\
(+4.2)\end{array}$ & \\
\hline
\end{tabular}




\begin{tabular}{|c|c|c|c|c|c|c|c|c|c|c|c|}
\hline & & $\begin{array}{l}1945 \\
(+4.9)\end{array}$ & & & & & & & & $\begin{array}{l}2016 \\
(+3.7)\end{array}$ & \\
\hline & & $\begin{array}{l}1946 \\
(+6.9)\end{array}$ & & & & & & & & & \\
\hline & & $\begin{array}{l}1947 \\
(-3.9)\end{array}$ & & & & & & & & & \\
\hline & & $\begin{array}{l}1960 \\
(-8.2)\end{array}$ & & & & & & & & & \\
\hline & & $\begin{array}{l}1965 \\
(-5.9)\end{array}$ & & & & & & & & & \\
\hline & & $\begin{array}{l}1984 \\
(-3.8)\end{array}$ & & & & & & & & & \\
\hline & & $\begin{array}{l}2007 \\
(+5.2)\end{array}$ & & & & & & & & & \\
\hline & & $\begin{array}{l}2012 \\
(+9.0)\end{array}$ & & & & & & & & & \\
\hline & & $\begin{array}{l}2016 \\
(+4.4)\end{array}$ & & & & & & & & & \\
\hline \multicolumn{12}{|c|}{ Ensemble Monthly Averages $\left({ }^{\circ} \mathrm{C}\right)$} \\
\hline-1.4 & 0.6 & 6.4 & 12.8 & 18.0 & 23.0 & 25.4 & 24.7 & 20.4 & 14.1 & 6.7 & 0.7 \\
\hline
\end{tabular}

Hemisphere, along with the location and effects of the Mediterranean Jet Stream. Table 3.5 also illustrates the anomalous rising temperatures that have been observed across the region, and the lack of cool temperature occurrences is assuredly a reflection of that. 
Table 3.5. The 45 southwest RUS (swRUS) temperature anomaly events listed in chronological order per month from January 1944 to December 2016. Temperature deviation from monthly mean listed next to events, in degrees Celsius $\left({ }^{\circ} \mathrm{C}\right)$.

\begin{tabular}{|c|c|c|c|c|c|c|c|c|c|c|c|}
\hline Jan. & Feb. & Mar. & April & May & June & July & Aug. & Sept. & Oct. & Nov. & Dec. \\
\hline 1950 & 1954 & 1952 & 1975 & 2013 & & 1999 & 1946 & 1966 & 1946 & 1953 & 2002 \\
\hline$(-10.12)$ & (?) & $(-7.81)$ & $(+5.09)$ & $(+5.26)$ & & $(+3.95)$ & $(+4.26)$ & $(-3.54)$ & $(-5.12)$ & $(-4.60)$ & $(-6.58)$ \\
\hline 1954 & 1956 & 1963 & 1987 & & & 2001 & 1972 & 1969 & 1974 & 1956 & \\
\hline$(-8.52)$ & $(-11.74)$ & $(-6.21)$ & $(-5.01)$ & & & $(+4.35)$ & $(+4.66)$ & $(-3.44)$ & $(+4.18)$ & $(-5.30)$ & \\
\hline 1963 & 2002 & 1987 & 2012 & & & 2002 & 2010 & 1973 & 1976 & 1959 & \\
\hline$(-8.82)$ & $(+8.06)$ & $(-6.51)$ & $(+5.19)$ & & & $(+3.75)$ & $(+6.46)$ & $(-3.84)$ & $(-4.92)$ & $(-4.50)$ & \\
\hline $\begin{array}{l}1972 \\
\end{array}$ & & $\begin{array}{l}1989 \\
\end{array}$ & & & & 2010 & & 1993 & & 1993 & \\
\hline$(-7.92)$ & & $(+5.69)$ & & & & $(+5.45)$ & & $(-3.54)$ & & $(-8.40)$ & \\
\hline 1987 & & 1990 & & & & & & 1994 & & 1996 & \\
\hline$(-8.32)$ & & $(+5.69)$ & & & & & & $(+5.16)$ & & $(+4.40)$ & \\
\hline & & $\begin{array}{r}2002 \\
(+5.69)\end{array}$ & & & & & & & & $\begin{array}{c}1998 \\
(-5.60)\end{array}$ & \\
\hline & & $\begin{array}{c}2007 \\
(+5.99)\end{array}$ & & & & & & & & $\begin{array}{c}2010 \\
(+7.10)\end{array}$ & \\
\hline & & $\begin{array}{c}2008 \\
(+5.89)\end{array}$ & & & & & & & & $\begin{array}{c}2013 \\
(+4.80)\end{array}$ & \\
\hline & & $\begin{array}{c}2014 \\
(+5.79)\end{array}$ & & & & & & & & & \\
\hline \multicolumn{12}{|c|}{ Ensemble Monthly Averages $\left({ }^{\circ} \mathrm{C}\right)$} \\
\hline-7.42 & -6.97 & -1.75 & 7.65 & 14.65 & 18.33 & 19.87 & 18.88 & 13.09 & 6.29 & -0.182 & -4.76 \\
\hline
\end{tabular}




\section{CHAPTER 4. DECEMBER 1889 AND MARCH 2012 CASE STUDIES}

\subsection{Conditions over North America}

Here two case studies of extremely warm events from the central USA are examined as researchers have long associated ridging and blocking with cold periods (e.g., Quiroz, 1984; Jensen, 2015). Also, Lupo et al. (2012b) studied the summer of 2010 drought that impacted western Russia, including the Belgorod region, which was due to strong and persistent blocking. Studying warm extremes in the cUSA has not been performed recently, although anomalous summer season warmth was studied previously (Namias, 1982, 1983; Lupo and Bosart, 1999). The former studies attributed anomalous summer season warmth to enhanced ridging, while the latter study examined precursors to the 1980 drought. However, none of these studies looked into the Pacific region flow regimes however.

During December 1889 , the mean temperature was $9.6{ }^{\circ} \mathrm{C}$ in the cUSA, and this was $8.9^{\circ} \mathrm{C}$ above the December mean and the second highest anomaly overall for the entire period of record (Table 3.1). For the month of March 2012, the comparative numbers were $15.4{ }^{\circ} \mathrm{C}$ and $9.0{ }^{\circ} \mathrm{C}$ above the March averages. This represents the largest months anomaly of the cUSA. Table 3.1 demonstrates that these two months were 1.6 and 2.5 times the three seasonal standard deviations above their respective seasonal averages. A surface map (Figure 4.3) demonstrates that the anomalous warmth of both months occurred throughout most of the conterminous USA, east of the Rocky Mountains, and in the case of 2012 temperature anomalies of $3-6{ }^{\circ} \mathrm{C}$ or greater were even observed in upstate NY and New England (National Climatic Data Center). Figure 
Figure 4.1. The observed temperature (blue) for December 1889 and March 2012 in the Columbia (cUSA) $\left({ }^{\circ} \mathrm{C}\right)$ compared to the mean (red) for Missouri.

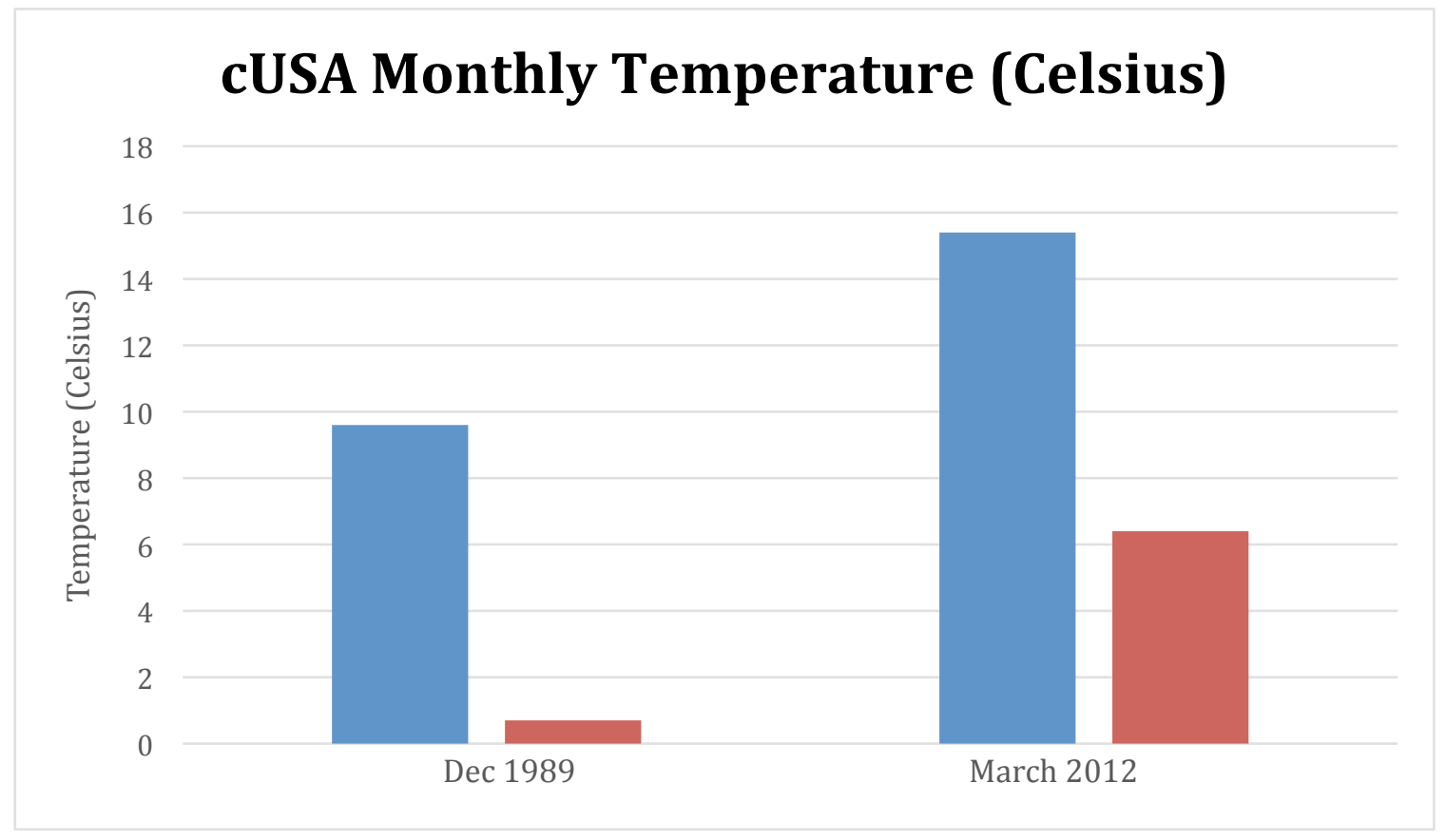

4.1 illustrates how high of a temperature difference in Celsius exists between the two months and their respective months average (both about 9 degrees).

The monthly precipitation for both case study months was wetter than normal for March of 2012, but drier for December 1889 (Figure 4.2), which is at least partially a function of the anomalous warmth. However, in spite of the anomalous warmth, neither of these months was among the wettest/driest on record. While it would be difficult to calculate the evaporation potential for each month, especially for December 1889, comparing each month to a month in the year with a mean temperature similar to that observed for both cases would demonstrate 
Figure 4.2. The observed precipitation (grey) for December 1889 and March 2012 in the cUSA mm compared to the mean (black) for Missouri.

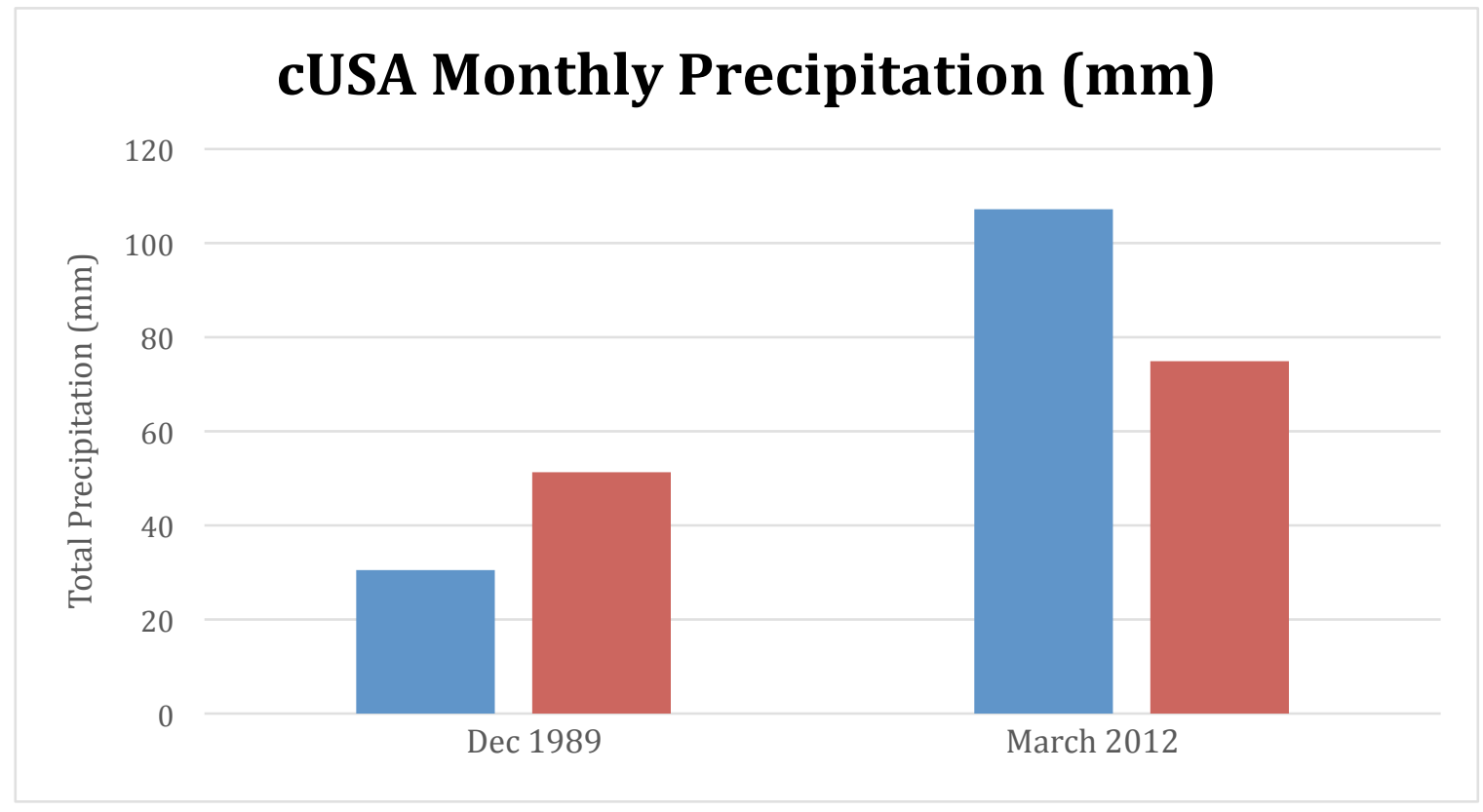

that the precipitation would be near normal for March 2012 (comparing to April and May), and drier than normal for December 1889 (comparing to October and November). December of 1889's precipitation total deviates notably less from the mean than in March of 2012, though this showed to be insignificant to this case study, as March marks the beginning of the wetter, higher variance Spring season in the Midwest.

Additionally, antecedent conditions did not provide strong indication that these extreme warm months would occur following them. The temperature data for the three preceding months would indicate that while it was warmer than normal before March 2012, it was cooler than normal before December 1889. Also, the three prior months featured above normal precipitation. 
Figure 4.3. The surface temperature anomaly maps for A) December 1889 , and B) March 2012. The units shown are $\left({ }^{\circ} \mathrm{C}\right)$. Generated by the NOAA/ESRL Physical Sciences Division.

A)

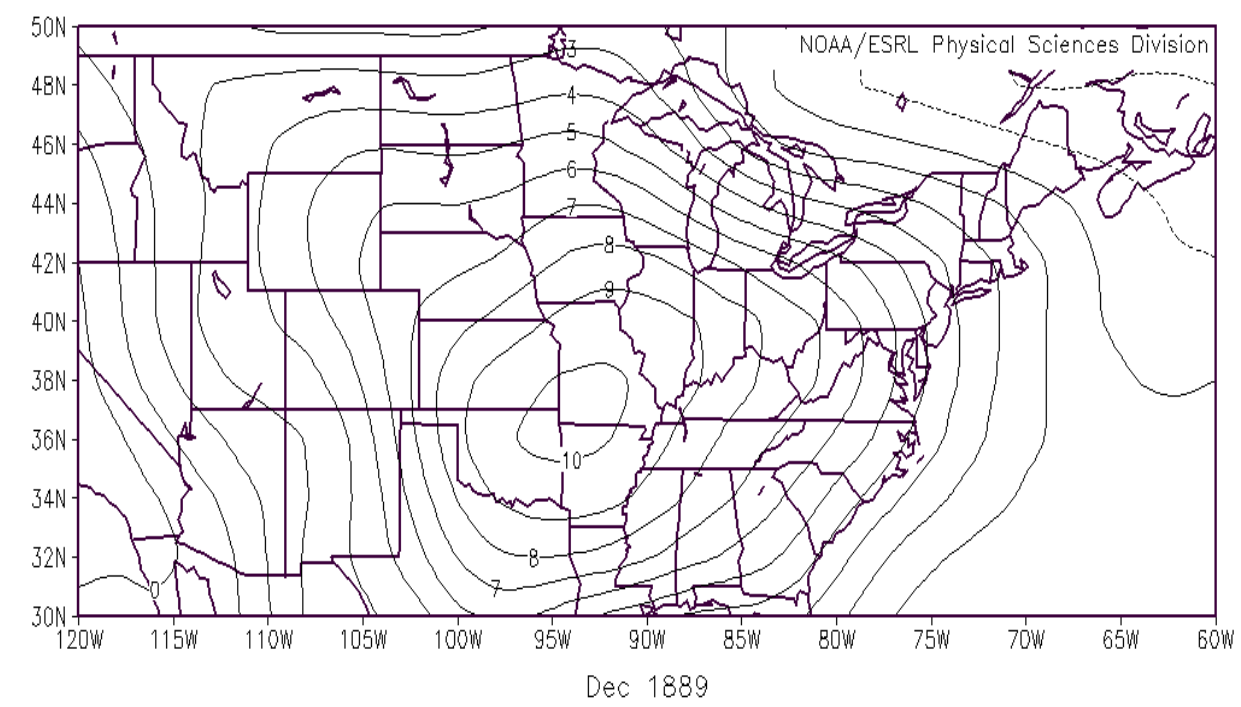

B)

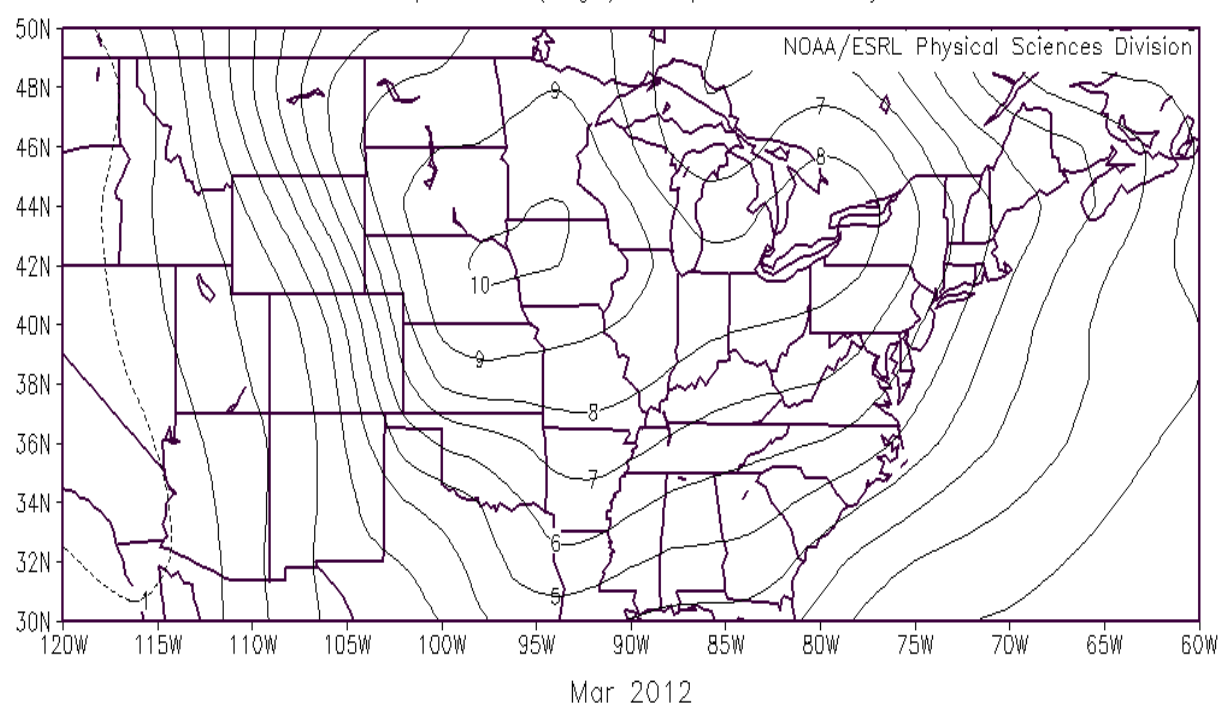


Figure 4.4. The mean $500 \mathrm{mb}$ Geopotential Height (DAM) Maps for A) December 1889, and B) March 2012. The contour interval is 50 meters (m). Map generated by the NOAA/ESRL Physical Sciences Division.

A)

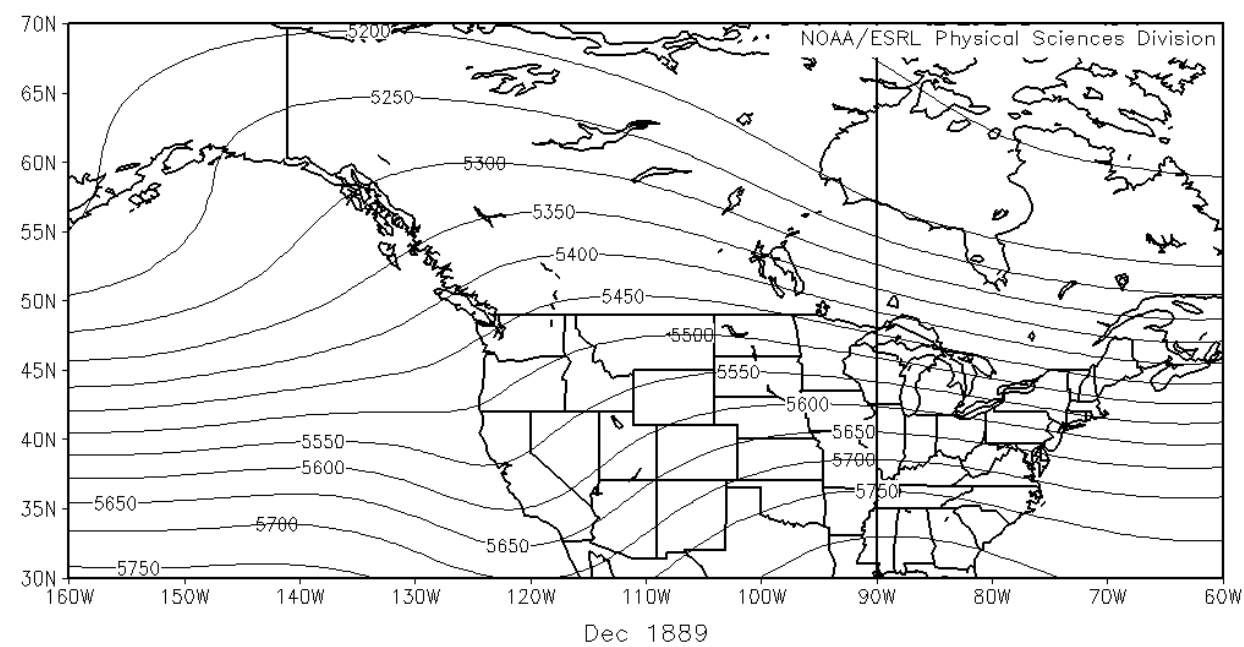

B)

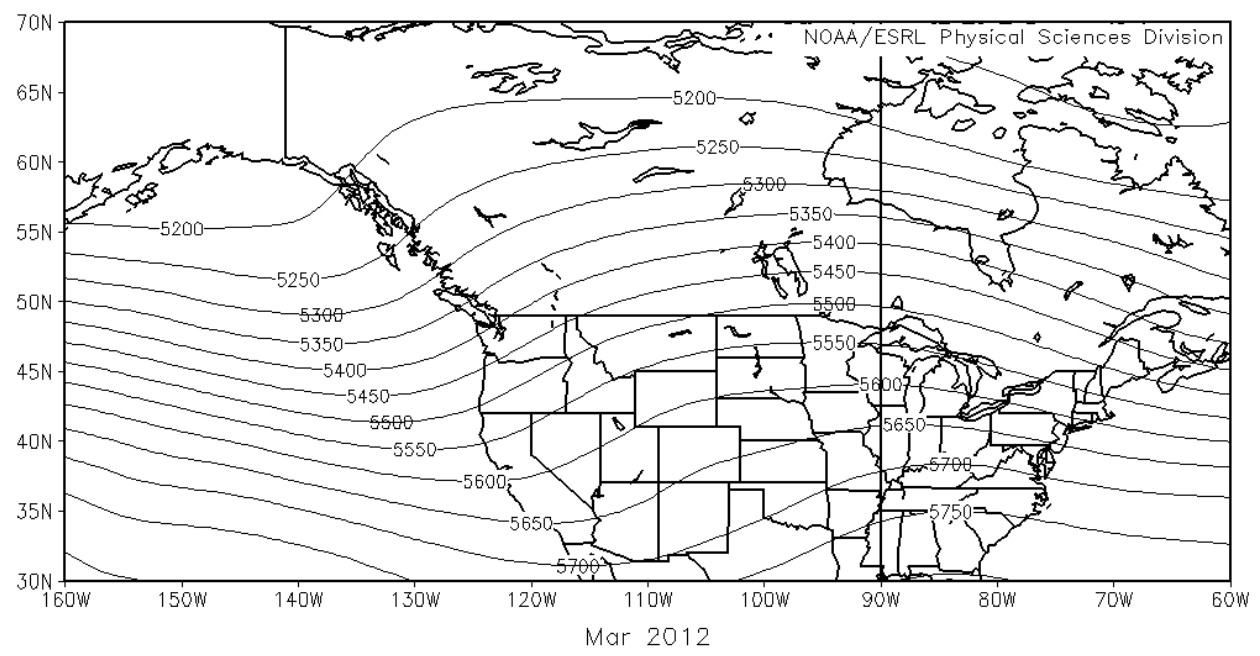


Figure 4.5. The $500 \mathrm{mb}$ mean Geopotential Height (m) Anomalies for A) December 1889, and B) March 2012. The contour interval is 30 meters (m). Map generated by the NOAA/ESRL Physical Sciences Division.

A)

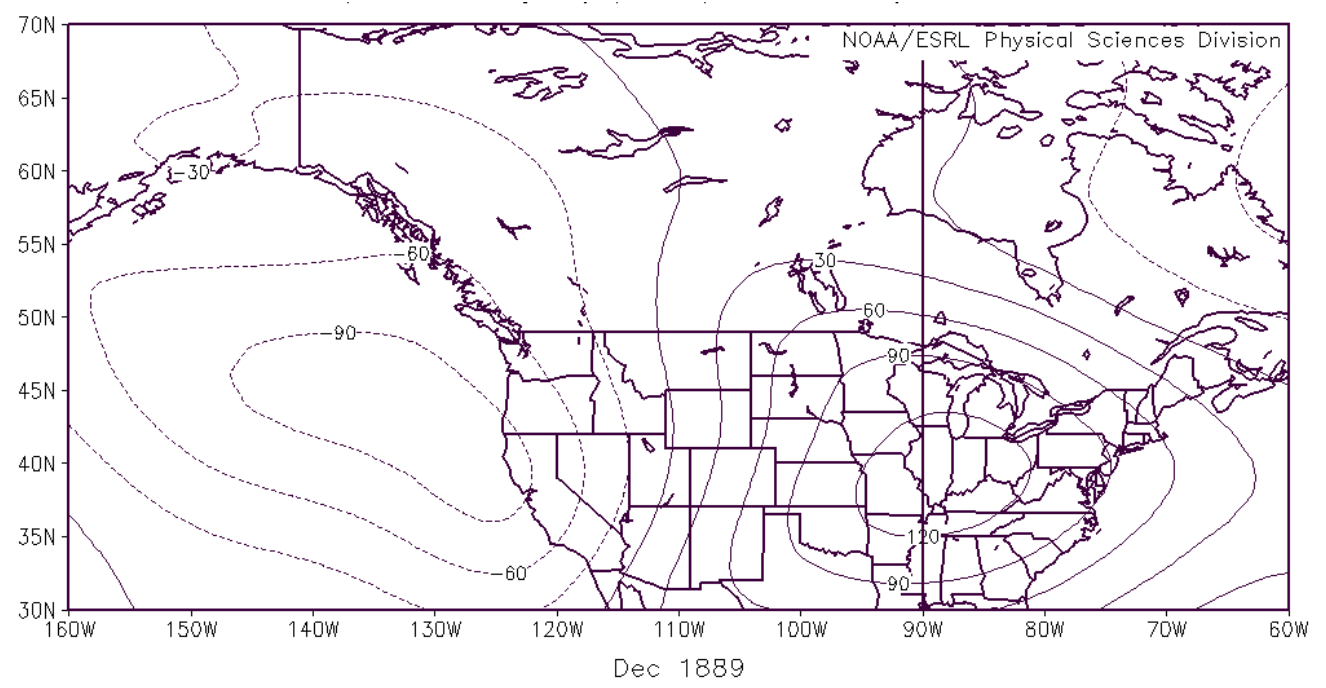

B)

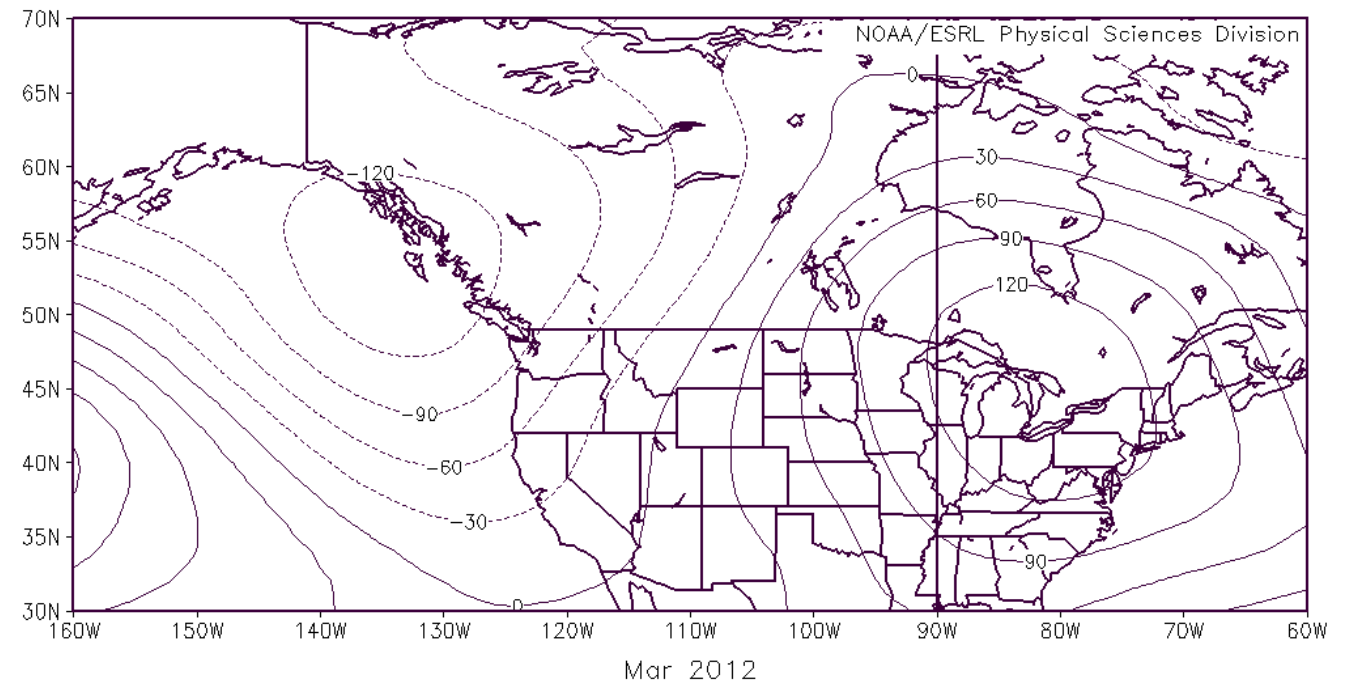




\subsection{Atmospheric Blocking}

Figure 4.4 illustrates the mean $500 \mathrm{mb}$ geopotential heights for North America during the two case study months. The two patterns are quite similar showing ridging over the east central USA, but weak troughing along the southern part of the West Coast. The $500 \mathrm{mb}$ ridging is just a little farther east in the March 2012 case than in the December of 1889 event, as shown by looking at the anomaly chart in Figure 4.5. The anomalies in Figures $4.3(500 \mathrm{mb})$ and 4.5 (surface) are remarkably similar in magnitude and coverage as well. The two figures demonstrated a flow regime similar across the Midwest USA, suggesting persistent warm air advection from the southwest may have contributed to the higher than average temperatures seen throughout the months.

During the extreme warm months, there was anomalous ridging over North America, while it is well known (e.g., Quiroz, 1984; Lupo et al. 2008b) that anomalously cold months are associated with atmospheric blocking over the Pacific Ocean Basin, as stated earlier. Examining the occurrence of blocking for the warm December 1889 and March 2012 months, demonstrated there was no blocking in the Pacific Region Basin. In March 2012, a very strong zonal pattern dominated the Northern Hemisphere (positive Arctic Oscillation - AO). However, just as found for the precursor surface records, there was no indication that there was more or less blocking than usual in the three months prior (Winter 2011-2012) over the Pacific Region. The only similarity in the precursor conditions was that both years were characterized as La Niña (December 1889) or cold neutral (March 2012) (see http://coaps.fsu.edu). 
Additionally, there have been eleven anomalously warm extremes in the cUSA since July 1968 and during only three of these months did blocking occur over the Pacific Ocean Basin (one event - see GCC). In contrast during extreme cold months (16), blocking occurred during 10 of these months (14 events). These blocking events persisted for an average of 7.6 days, and their intensity was classified as typical for the winter season (3.50) using the Block Intensity (BI) of Wiedenmann et al. (2002). In swRUS, during the same time period there were 10 extremely cold months and all of these were associated with blocking in the Atlantic sector upstream (15 events). The blocking events persisted for 11.2 days and were associated with a mean BI of 3.78 . There were 22 extreme warm months in the swRUS region, and 21 of them were associated with blocking (32 events total) either over the region or downstream. These events persisted for 9.2 days with a BI of 2.76. While the values are typical for the primary season in which blocking occurred, the cold extremes were associated with longer-lived and stronger blocking events. 


\section{CHAPTER 5. DISCUSSION}

\subsection{ENSO Phase Patterns}

One factor closely analyzed to the extreme temperature anomalies of the cUSA region was the events respective ENSO phase classification. Figure 2.3 illustrates the fluctuation pattern the ENSO phases follow and that El Niño and La Niña seasons both are prone to experience stronger or weaker phases through the fluctuation process. Most intriguing was the El Niño and Neutral ENSO phases composing a significantly higher occurrence rate of anomalous temperature events than the La Niña seasons as charted in Table 3.2. This pattern suggests that the cUSA is most likely to experience such events when an El Niño season is transitioning to a La Niña, contrary to a La Niña season transitioning to an El Niño phase. For instance, there has never been an observed anomalous summer month during the La Niña season, and this is surely attributed to the moderate seasons that tend to accompany a La Niña to El Niño transition season (Newberry et al. 2016). This was the situation during both the case studies, as a strong El Niño season transitioned to a weak La Niña phase. It resulted in two of the most severe temperature cases observed, and is notable that this trend has sparked those warm events to occur. This ENSO transition trend is furthermore recognized by the Newberry et al. 2016 analysis of the spring-to-summer transition. It is concluded that summers temperatures are prone to a later onset during La Niña to El Niño, transitioning years, than for that from El Niño to La Niña years (Newberry et al. 2016).

Notable is how anomalous cool events have mostly occurred in similar transitioning years, though it was often a weak El Niño shifting to a strong La Niña, 
making for much circumstantial differences. Table 3.2 concisely projects the probability of an anomalous season (months) per respective ENSO phase and it is clear how the associated-transitioning upper air patterns across the cUSA are reflective upon surface observation. The frequency rates of temperature anomalies through the E1 Niño and Neutral ENSO phases directly relate to the spring/fall transitioning seasons.

Blocking in the Pacific region tended to result from meridional flowing La Niña seasons. With a piling ridge developed over the Eastern Pacific from the blocking, persistent cool temperatures flow across the cUSA region. A trough would develop southeast of Missouri, taking in the cooler air temperatures and complete the meridional flow pattern observed. Upstream blocking conditions were enhanced during the La Niña season, which correlated to some extreme cool events. In contrast, blocking conditions were suppressed during the EL Niño season, which enabled the zonal flow to persist through such phases. These circumstances were favorable for anomalously warm events in the cUSA, especially during strong El Niño seasons.

There showed to be little to no association between precipitation (wet/dry) events and their respective ENSO years. Through the cUSA region, Neutral-ENSO years produced the most extreme precipitation months. A higher occurrence of such months was seen in the La Niña years over its El Niño counterpart by a slim margin, however the spread is insignificant in size (.47 to .41 , respectively).

\subsection{Blocking Phenomena}

This study examined blocking events and analyzed their sizes and seasonal and interannual variability. Events were retrieved from the University of Missouri-Columbia 
blocking database and defined as blocking events using the definition of Lupo and Smith (1995). Upon retrieval, the found anomalous months were analyzed. Blocking events averaged per year have substantially risen to 33 from what used to be 21 to 27 events found in previous studies (Abraham et al. 2012). The growing number of blocking events coincides to the global mean temperature over land and water increasing, according to the National Oceanic and Atmospheric Administration. Abraham's study supports earlier research that predicted the annual number of blocks would increase with a rising global temperature. This pattern was observed in both regions, with temperatures shown to steadily rise through the two study periods (more substantially in the swRUS region).

Though blocking may not be as widely known as other meteorological phenomena, its effects can stretch a wide distance. Blocking has recently led to significant heat waves, droughts, and even flooding (Lupo et al. 2012). The trigger mechanism and termination of blocking events are not well understood and long-range forecasters lack the ability to accurately predict when a blocking event will form, let alone its duration, strength and exact location. This applies to blocking occurrence of all regions (Pacific, Atlantic, Continental), be it in the cUSA or the swRUS. In this study, the Pacific blocking or lack thereof was the most prominent occurring factor in relation to a cool or warm temperature events in the cUSA region. Despite its unpredictability, blocking was a worthy inclusion to this research study.

\subsection{Trending Warm Events}

As stated in Chapter 3.1, it is reasonable to consider that increasing temperatures across both regions are spawning more warm events and diminishing cool events. In 
swRUS, 18 of the last 22 temperature anomalies have been warm since 1988. This comes as much less of a surprise than for the cUSA region, for steadily rising temperatures has been an observed trend for nearly 30 years across Russia. The cUSA may be making a similar transition, albeit much earlier in the developmental stages of transition. A cool anomaly has not been observed since October of 2009 and dating back to 2001 , nine of the last 11 events have been associated with extreme warm conditions. This brought the tally of 96 total temperature events to a 50-46 warm occurrence edge. While it is a slim margin for both regions, when the entire sample sizes are taken into consideration, it is these recent trends that suggest a slate of more warm seasons (and anomalies) are to come. This could mostly be the case when meteorological circumstances (ENSO phase, interdecadal variability, blocking patterns, etc.) are favorable, as elaborated upon through Chapter 3 and case studied in Chapter 4. 


\section{CHAPTER 6. CONCLUSIONS}

A study of the occurrence of extremely warm, cold, wet, and dry months for extended time series of temperature and precipitation data for the Columbia (in cUSA) and swRUS study regions was conducted. The results showed that in both regions there was no general tendency toward the occurrence of warm versus cold anomalies when taking the entire time index into account, beyond what would be expected randomly. While the strongest raw temperature anomalies occurred during the winter months, the strongest normalized anomalies occurred during the transition seasons in both regions. Additionally, there were no long-term trends in the preference of warm or cold anomalies with time in the study region, but for swRUS warm (cold) anomalies occurred preferentially after (before) 1990. Both results are consistent with the strength of longterm temperature trends.

The long-term variability showed significant interdecadal variability in temperature or precipitation, except for that associated precipitation and the PDO in the cUSA. With respect to ENSO, there was a tendency toward the more frequent occurrence of extreme temperature anomalies during El Niño and neutral years in the cUSA, but during El Niño and La Niña in swRUS. For precipitation, neutral years (neutral and El Niño) were far more likely to feature precipitation extremes.

Examining the case studies demonstrated anomalous ridging over much of the eastern USA, while there was no Pacific Region blocking during either month. Both anomalies were of similar magnitude and extent. Neither warm anomaly was accompanied by a consistent precursor signal three months in advance. In examining the 
association of extremes with upstream blocking, during extremely warm (cold) months, the occurrence of blocking is suppressed (enhanced) in the cUSA. These blocking events were typical of the region in terms of persistence and intensity. In swRUS, there were 32 extremely warm or cold months since 1968 , and nearly every one of these were associated with blocking. In the case of cold (warm) months, blocking occurred upstream (over or downstream) of the region. 
The following figures represent a time series of 20 cUSA temperature events, charted by the NOAA's Earth System Research Laboratory (ESRL) division. The temporal coverage ranges from January $1^{\text {st }}, 1979$ to June $30^{\text {th }}, 2016$. This was achieved through the archived NCEP/NARR (North American Regional Reanalysis) pressure level files. The charts are $500 \mathrm{mb}$, geopotential monthly height averages, per each respective anomaly (month) following the methodology discussed in section 2.2. The Python Program coding language provided the height chart illustrations. 


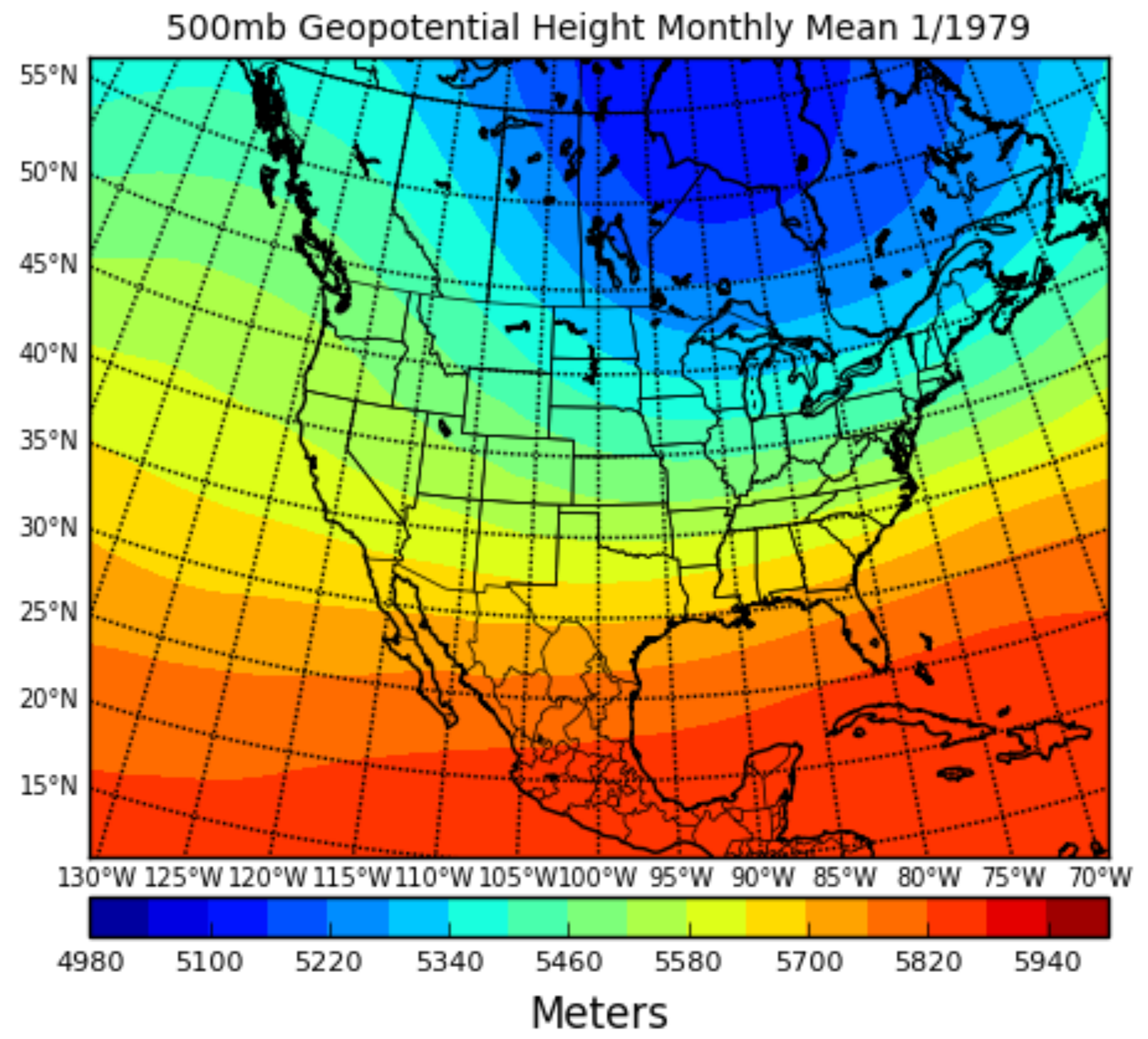

Figure A.1. January $1979\left(-7.6^{\circ} \mathrm{C}\right) 500 \mathrm{mb}$ averaged chart. A strong meridional flow present through the cUSA area, with a digging trough from the North. 
500mb Geopotential Height Monthly Mean 7/1980

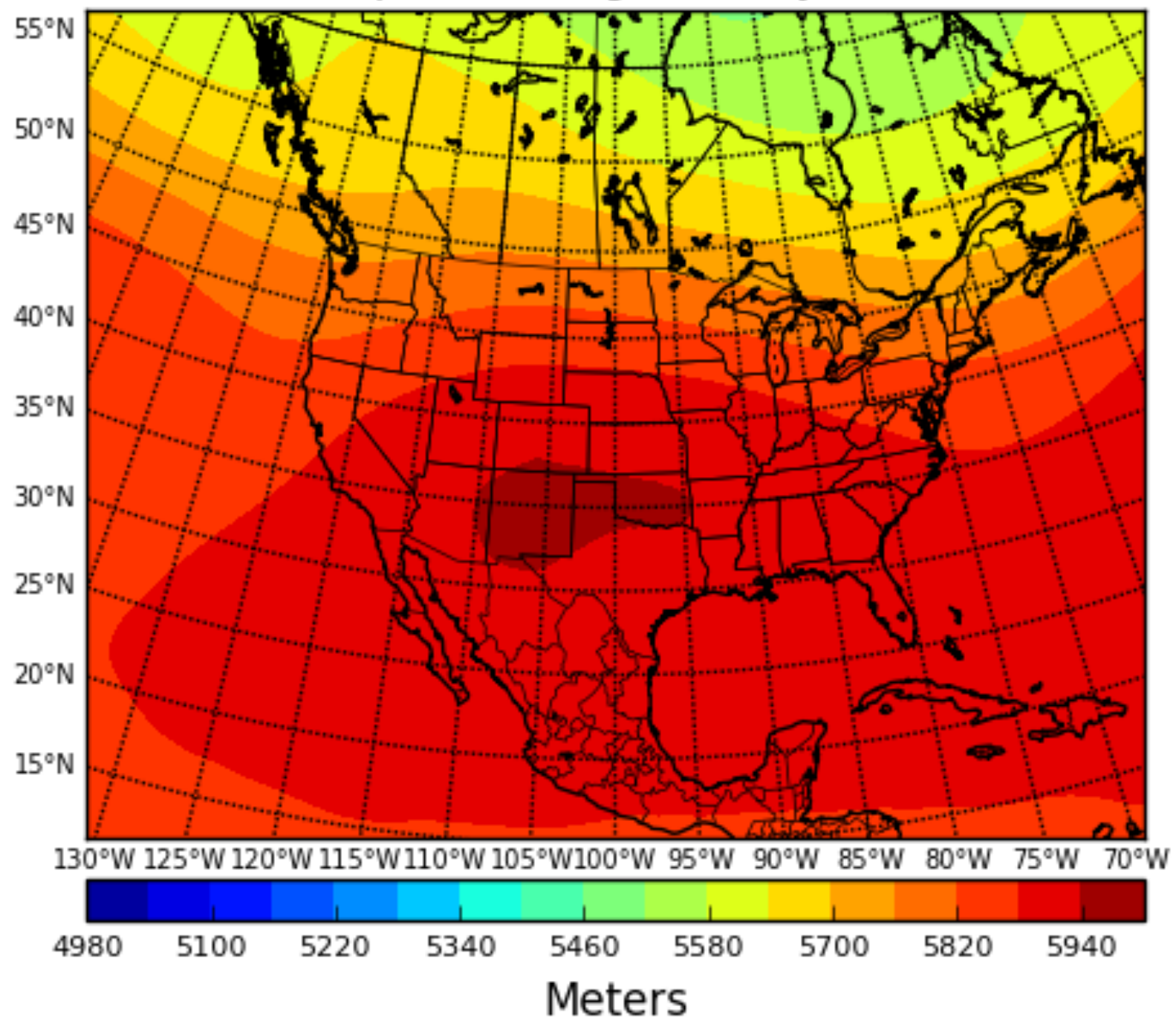

Figure A.2. July $1980\left(+5.1{ }^{\circ} \mathrm{C}\right) 500 \mathrm{mb}$ averaged chart. Heights rose extremely high across Tornado Alley, strongly effecting cUSA region. Persistent zonal flow observed. 


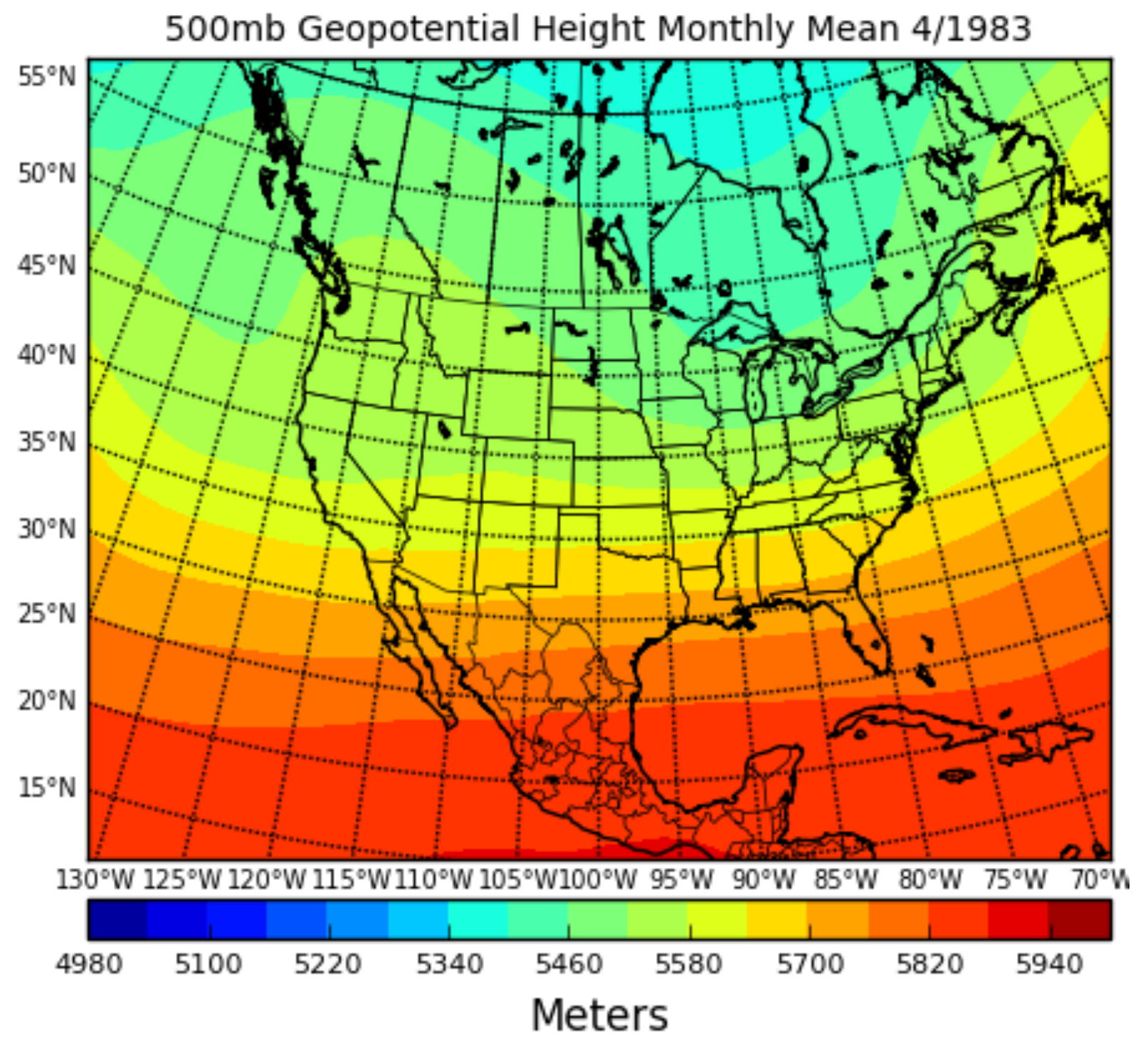

Figure A.3. April $1983\left(-3.8^{\circ} \mathrm{C}\right) 500 \mathrm{mb}$ averaged chart. Very polarizing illustration, showing very zonal in the Southern half and meridional in the North. The Central USA region just catches the cooler Northwestern flow. 


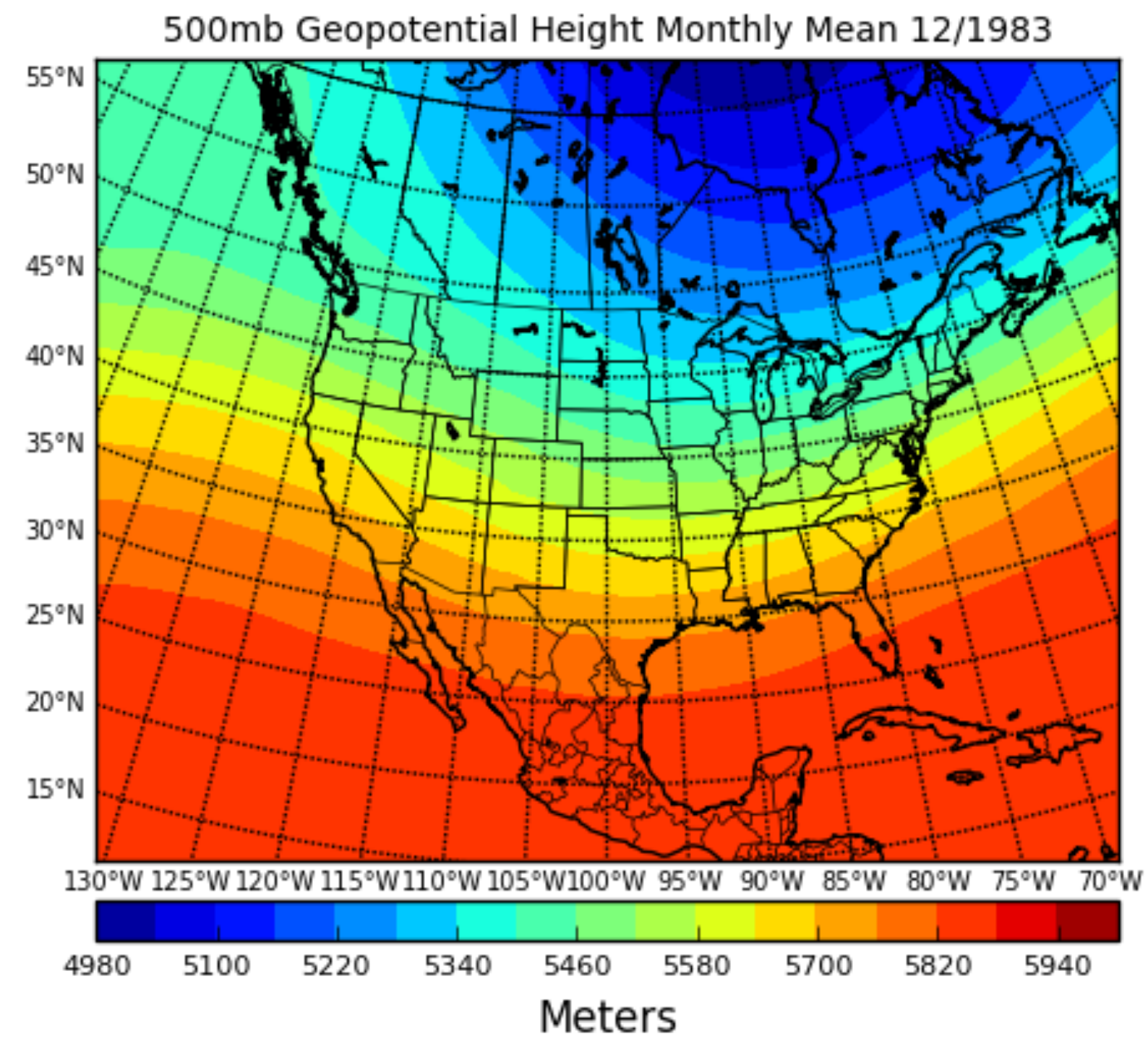

Figure A.4. December $1983\left(-8.7^{\circ} \mathrm{C}\right) 500 \mathrm{mb}$ averaged chart. A trough is present across the entire USA. Definitely contributed to cooler temperatures and flowing pressure systems across cUSA. 


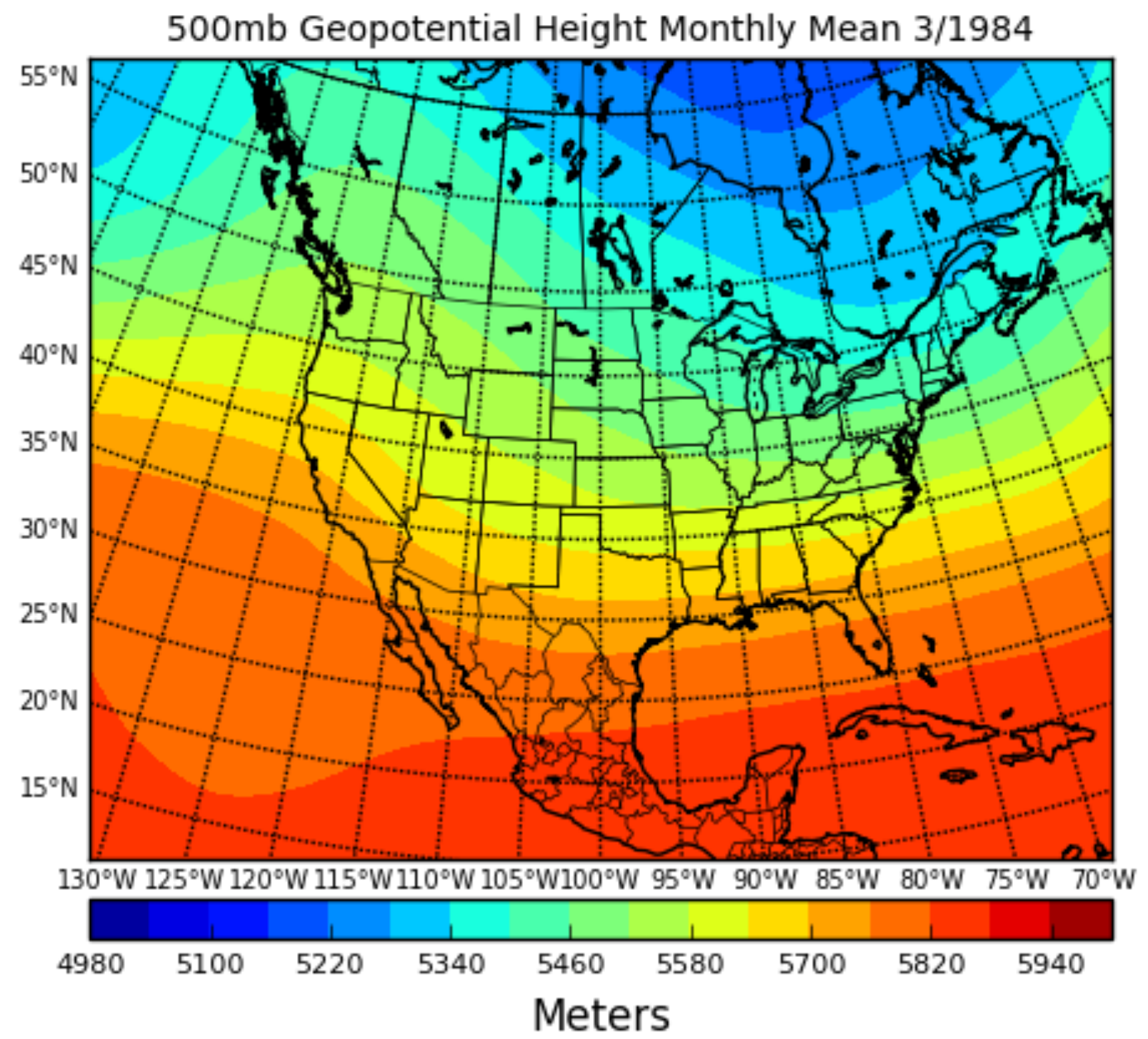

Figure A.5. March $1984\left(-3.8^{\circ} \mathrm{C}\right) 500 \mathrm{mb}$ averaged chart. A piling ridge over the Pacific Coast and prominent trough throughout the Southern states give the cUSA a consistent Northwesterly flow throughout the month. 


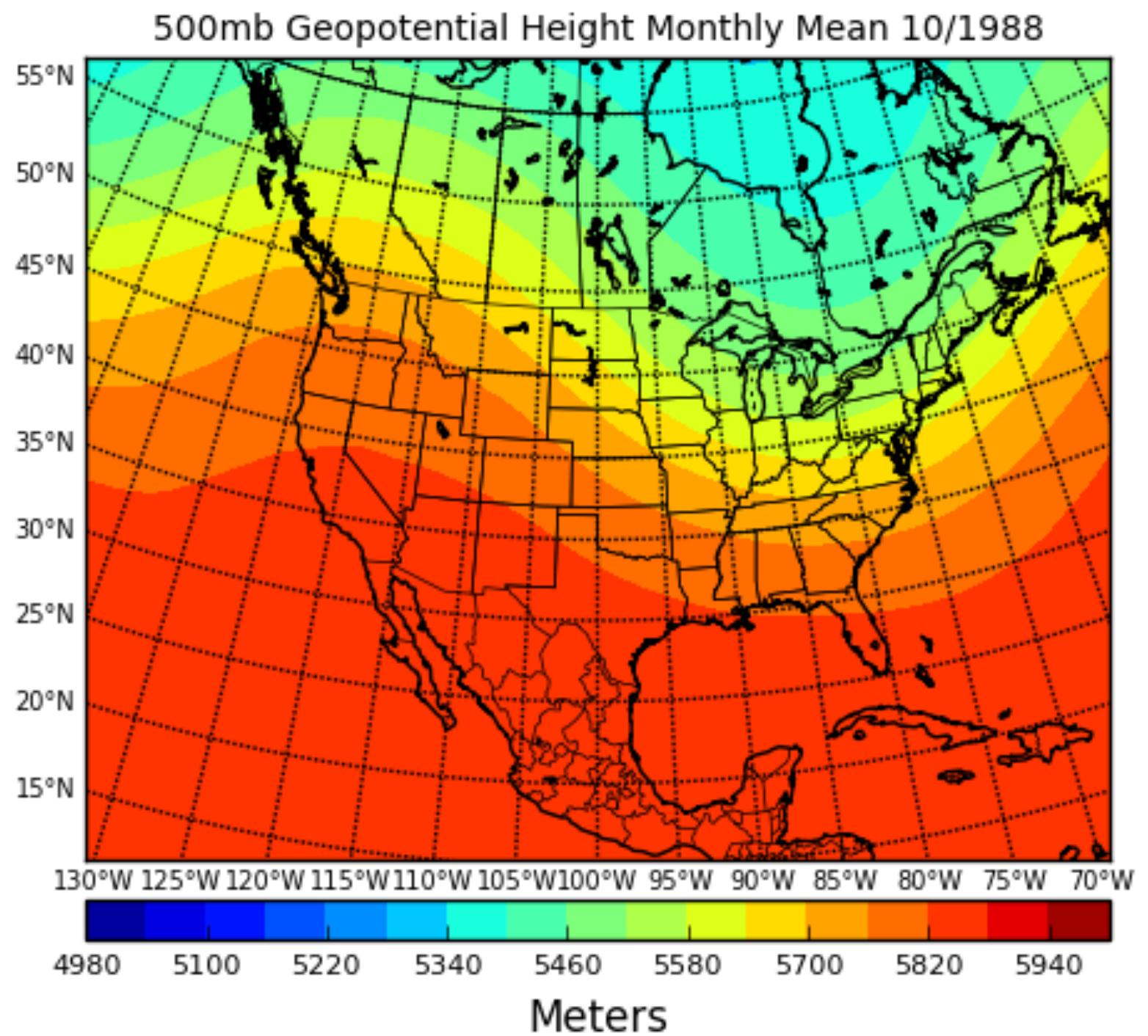

Figure A.6. October $1988\left(-3.6^{\circ} \mathrm{C}\right) 500 \mathrm{mb}$ averaged chart. A consistent piling ridge and digging trough contribute to a meridional flow pattern across the cUSA, dropping temperatures. 


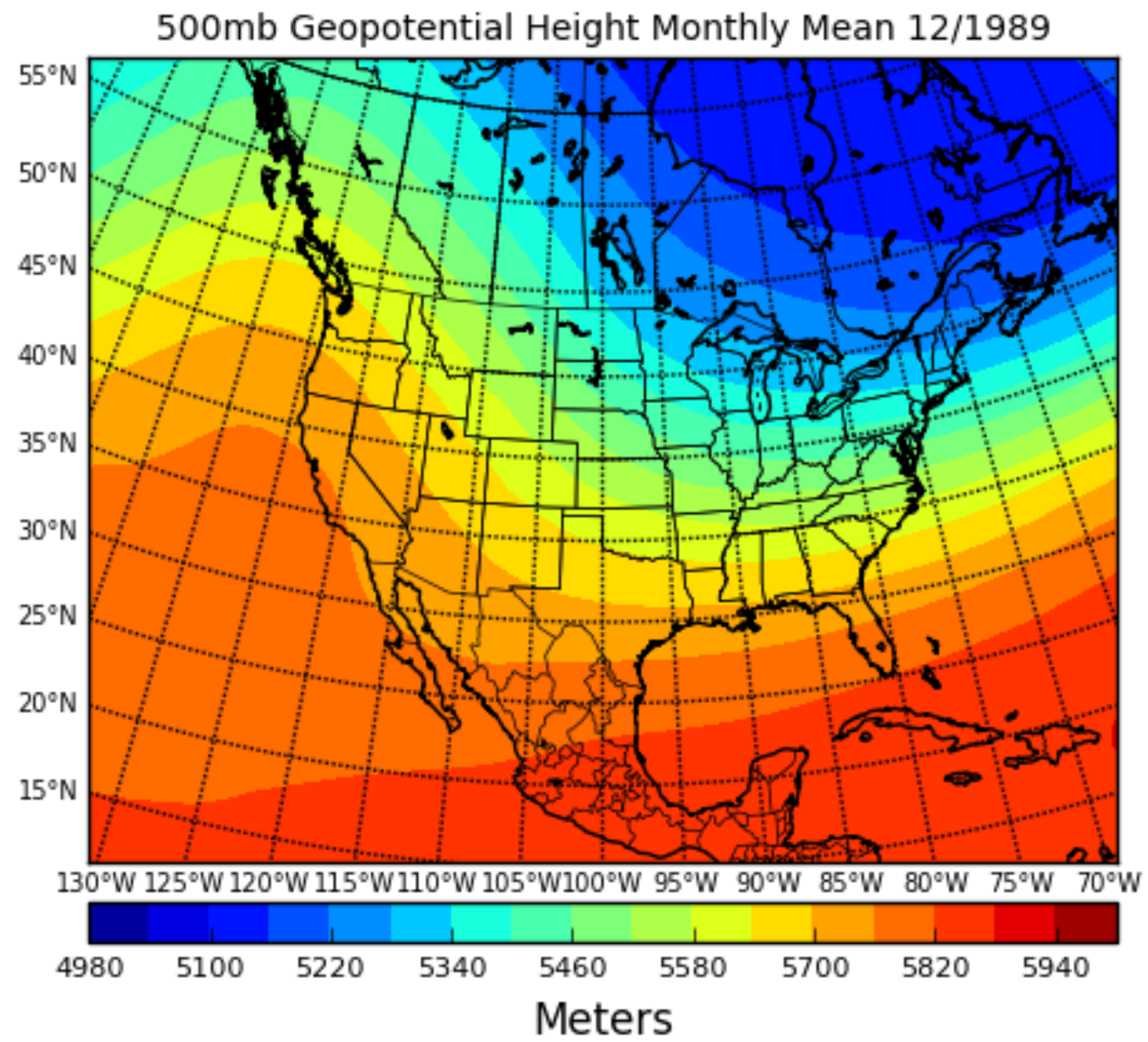

Figure A.7. December $1989\left(-6.5^{\circ} \mathrm{C}\right) 500 \mathrm{mb}$ averaged chart. A much stronger ridge/trough pairing across the USA no doubt contributes to a much more frigid December. 


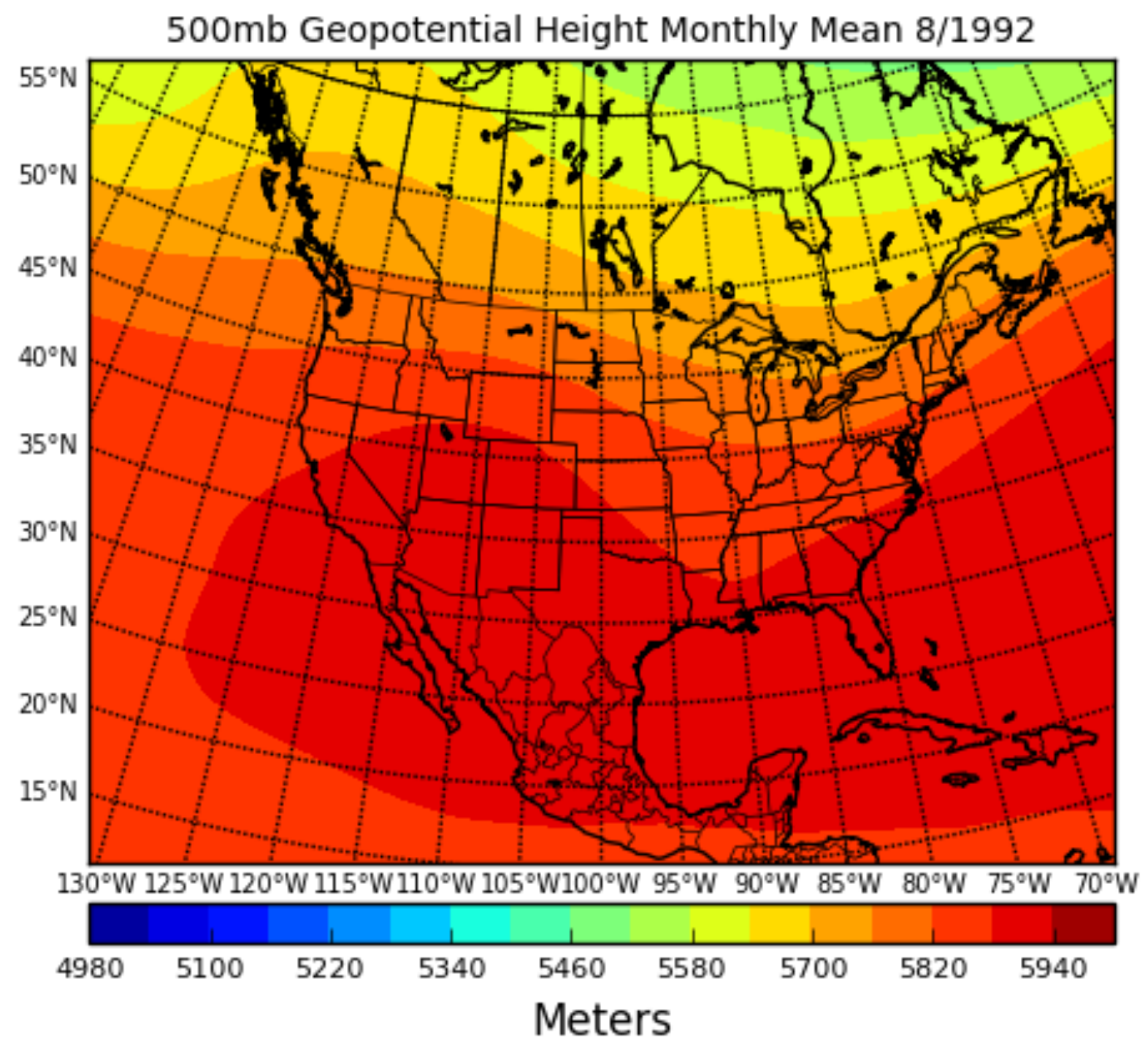

Figure A.8. August $1992\left(-3.4^{\circ} \mathrm{C}\right) 500 \mathrm{mb}$ averaged chart. Higher heights observed alongside a meridional flow pattern observed across cUSA region. 


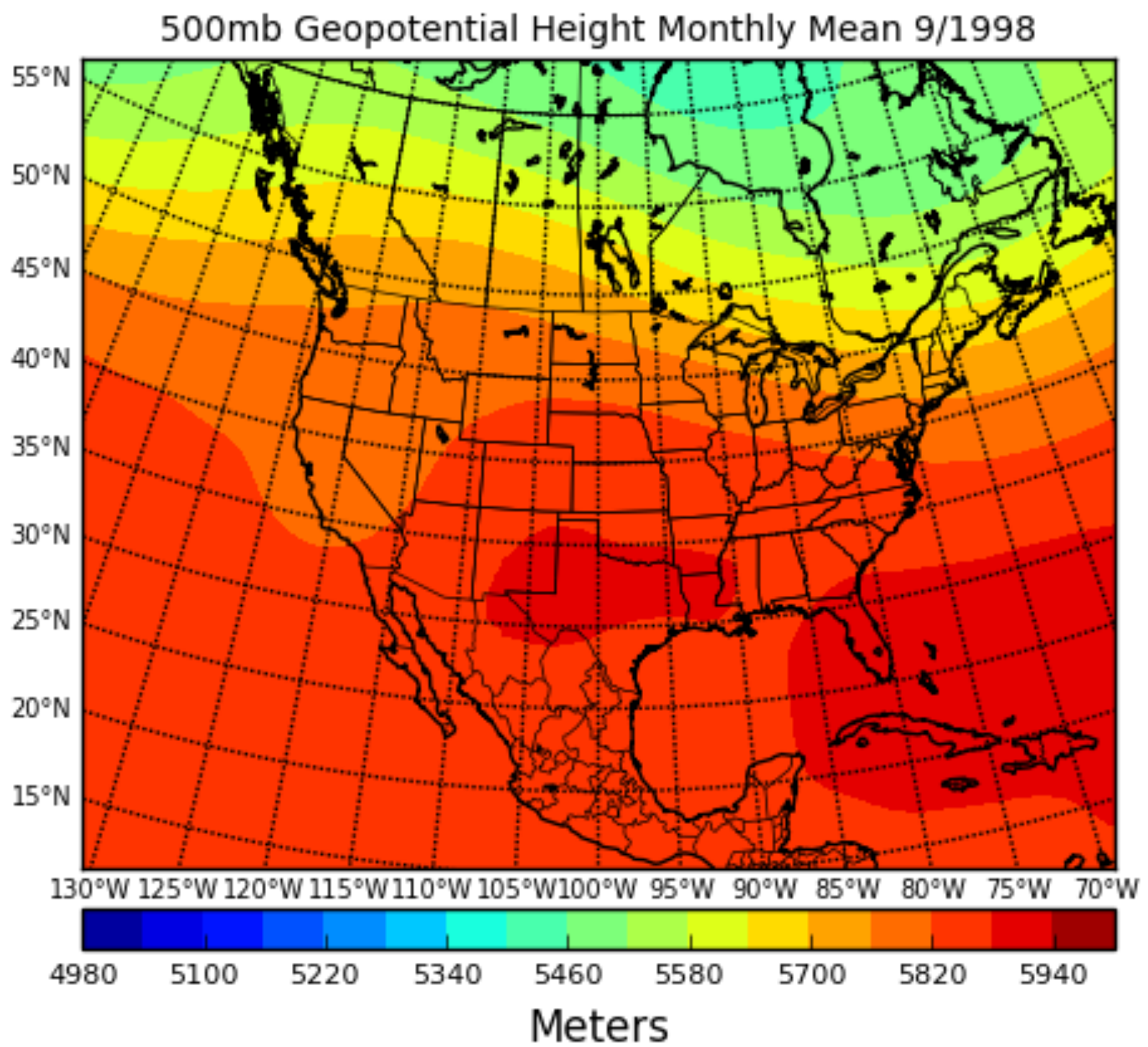

Figure A.9. September $1998\left(+4.9^{\circ} \mathrm{C}\right) 500 \mathrm{mb}$ averaged chart. High heights and persistent zonal flow observed across cUSA region, with a piling ridge sitting over Nebraska. 


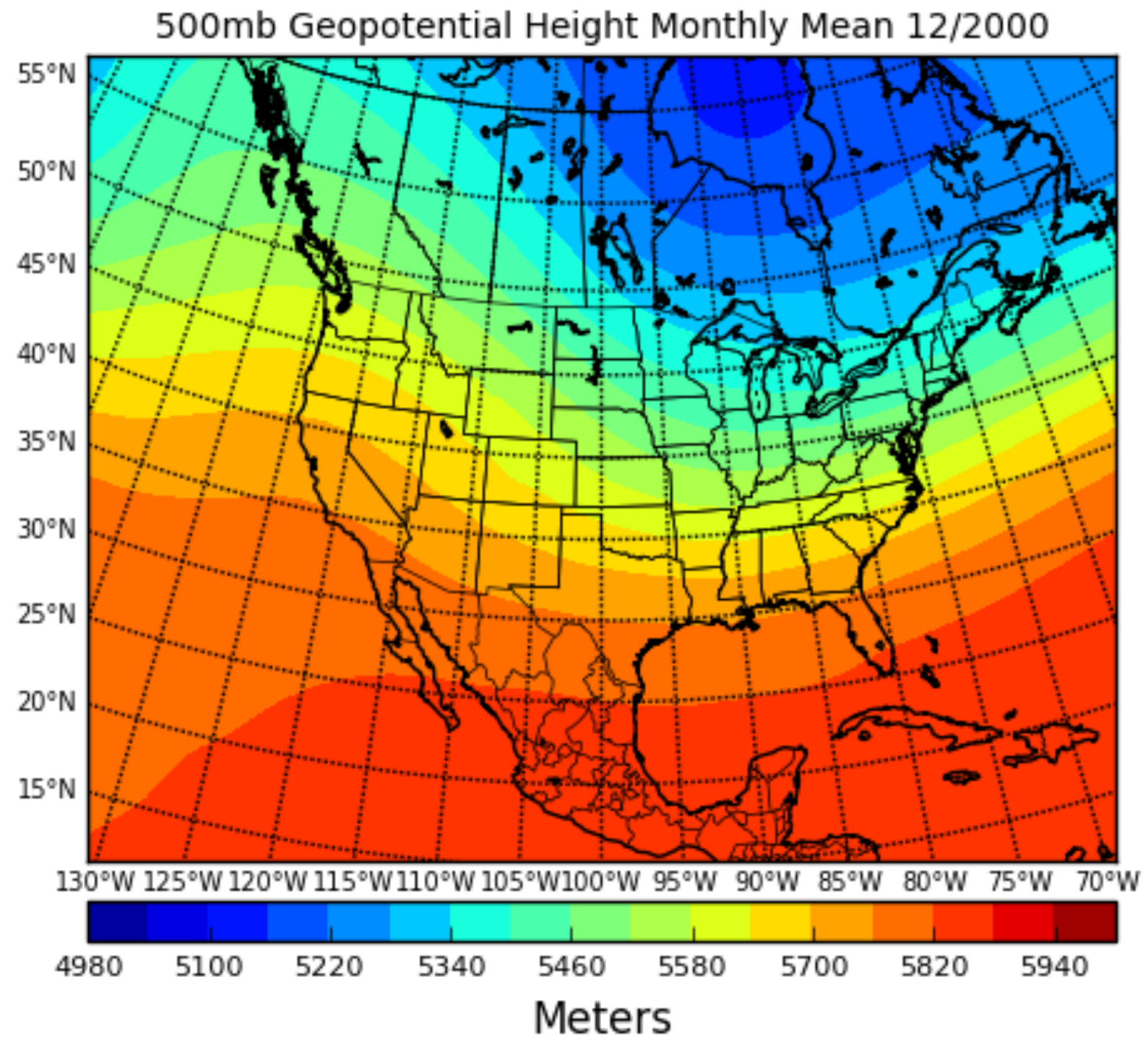

Figure A.10. December $2000\left(-7.4{ }^{\circ} \mathrm{C}\right) 500 \mathrm{mb}$ averaged chart. A strong digging trough is located through Missouri and Kentucky, resulting in a definitive meridional flow within the cUSA, and a large spread in height values. 


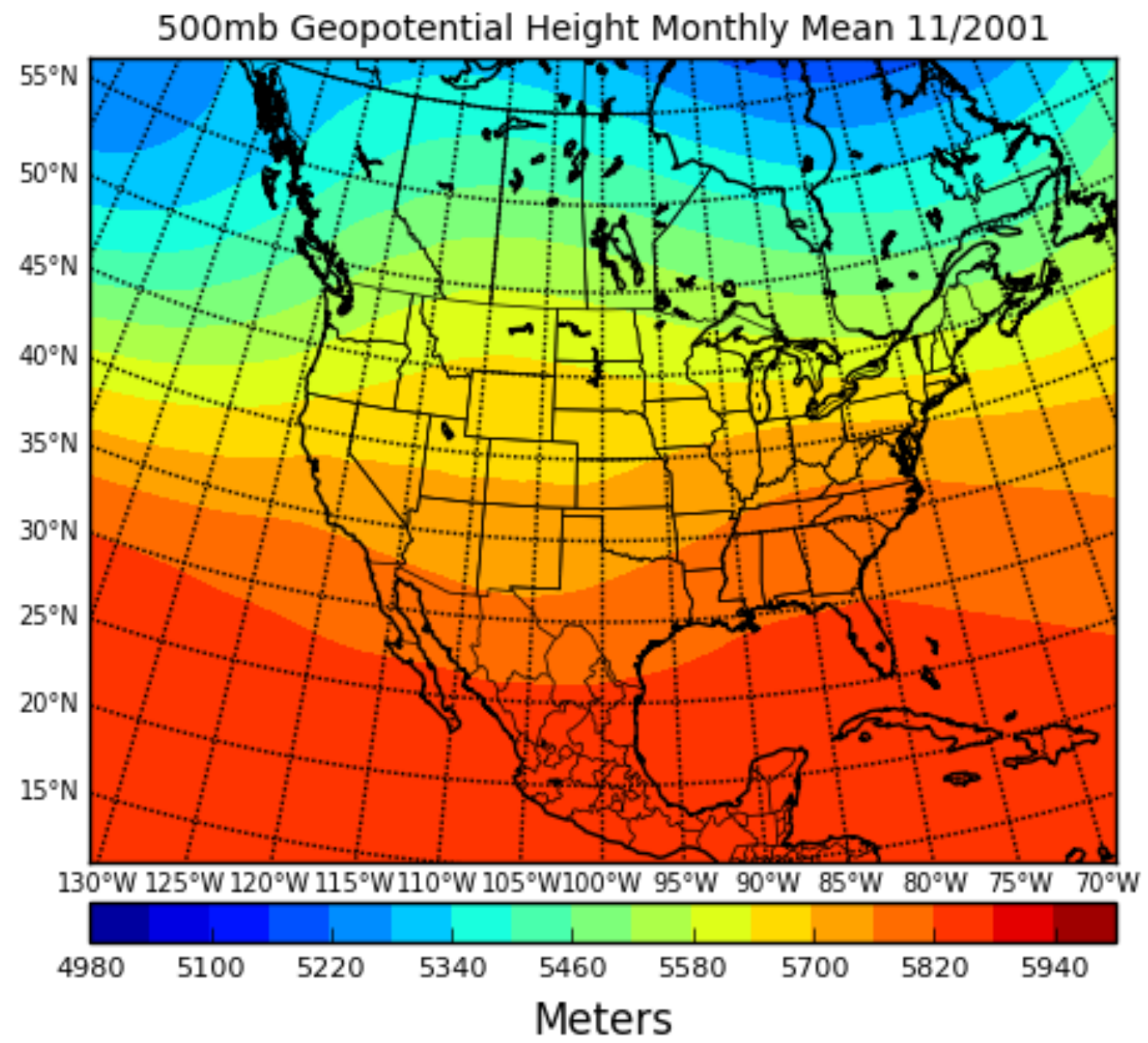

Figure A.11. November $2001\left(+3.7^{\circ} \mathrm{C}\right) 500 \mathrm{mb}$ averaged chart. An overall zonal flow with no cooler airflow from the North leads to an anomalously warm Nov. in the cUSA region. 


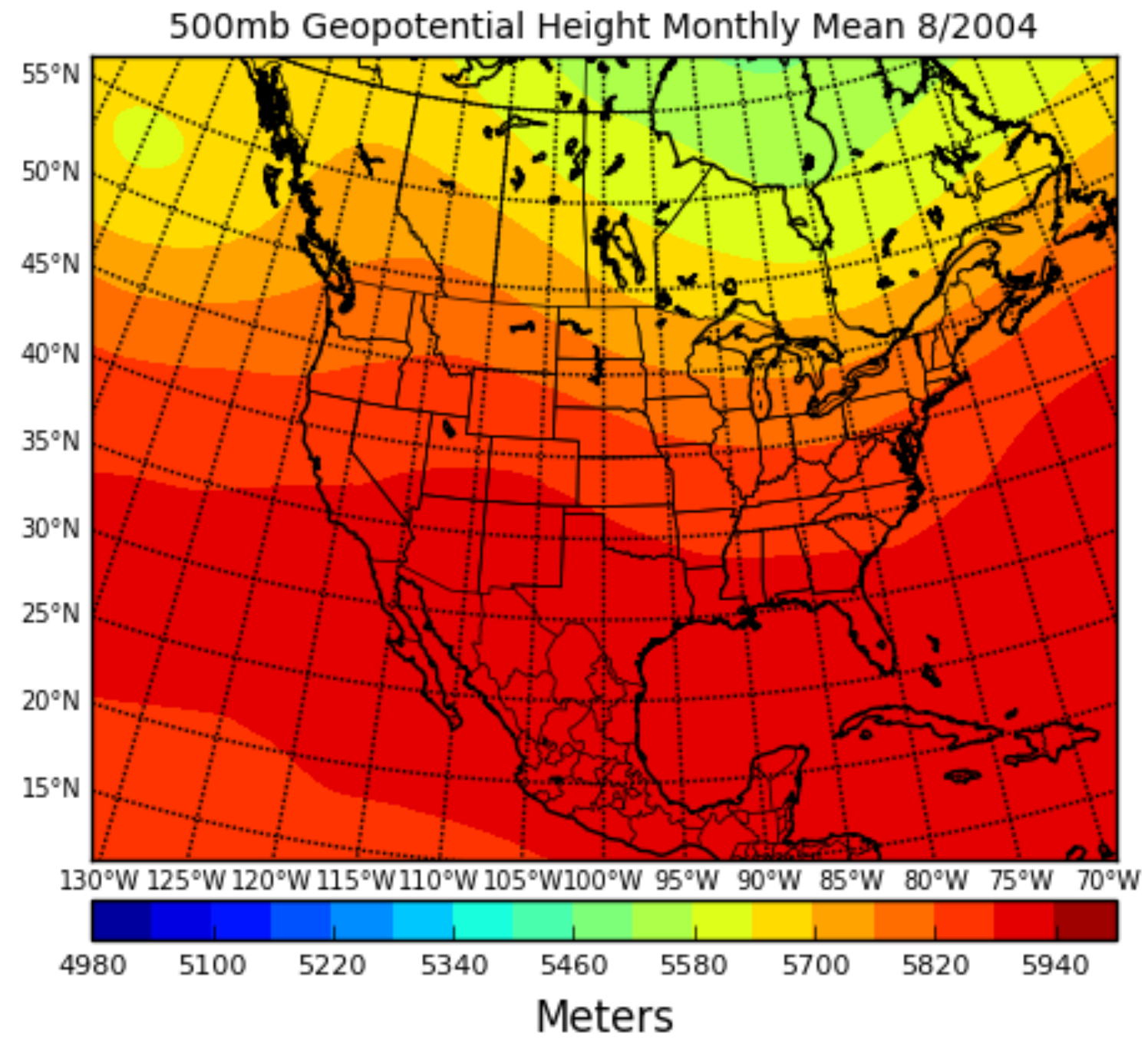

Figure A.12. August $2004\left(-3.5^{\circ} \mathrm{C}\right) 500 \mathrm{mb}$ averaged chart. This is nearly identical to what is observed in Figure A.8. where higher heights are observed across the cUSA but a slight meridional flow pattern lead to a cooler August. 


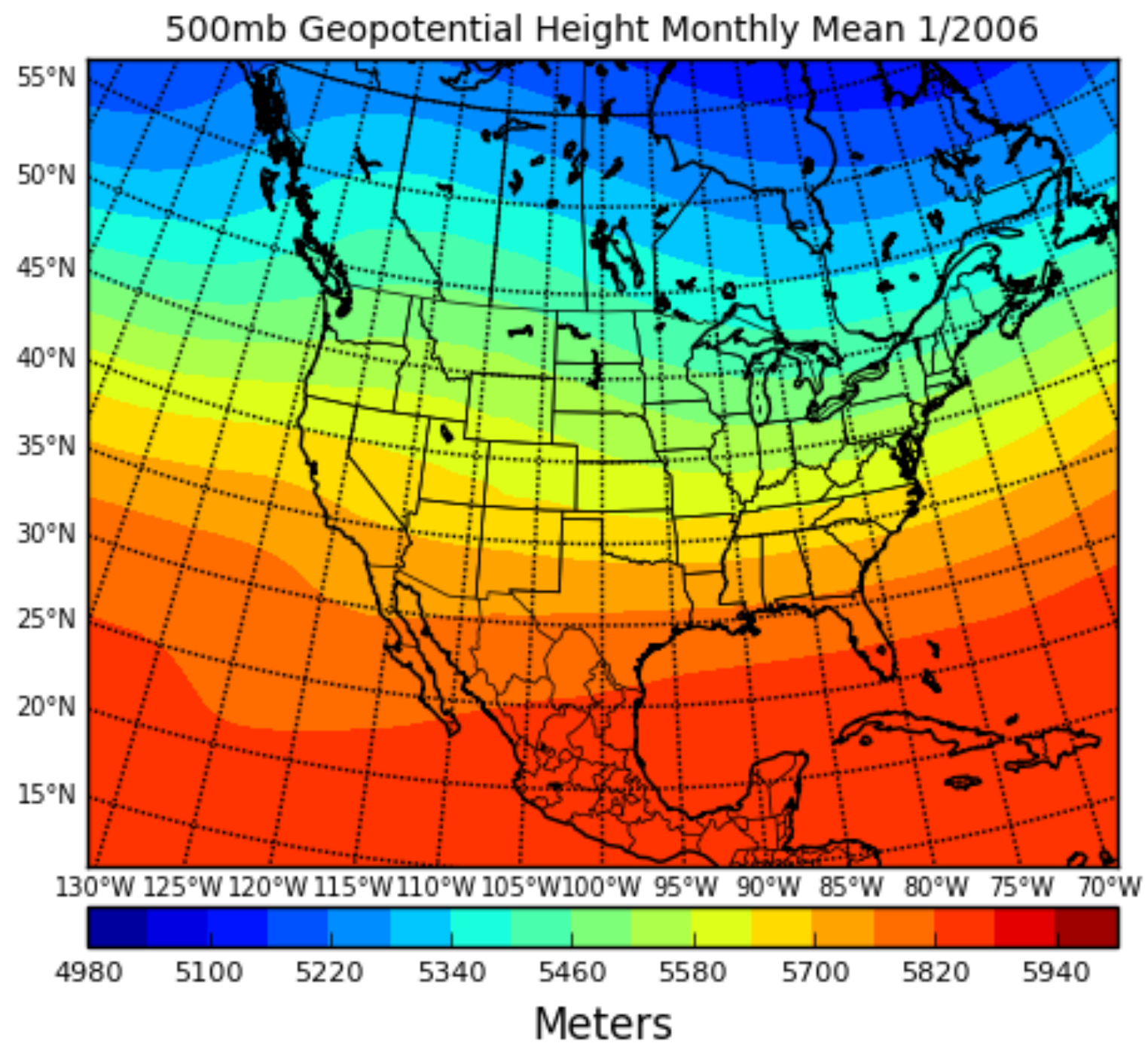

Figure A.13. January $2006\left(+6.4{ }^{\circ} \mathrm{C}\right) 500 \mathrm{mb}$ averaged chart. Very warm January month for the cUSA, due to a consistent zonal flow pattern and lack of Northern systems. 


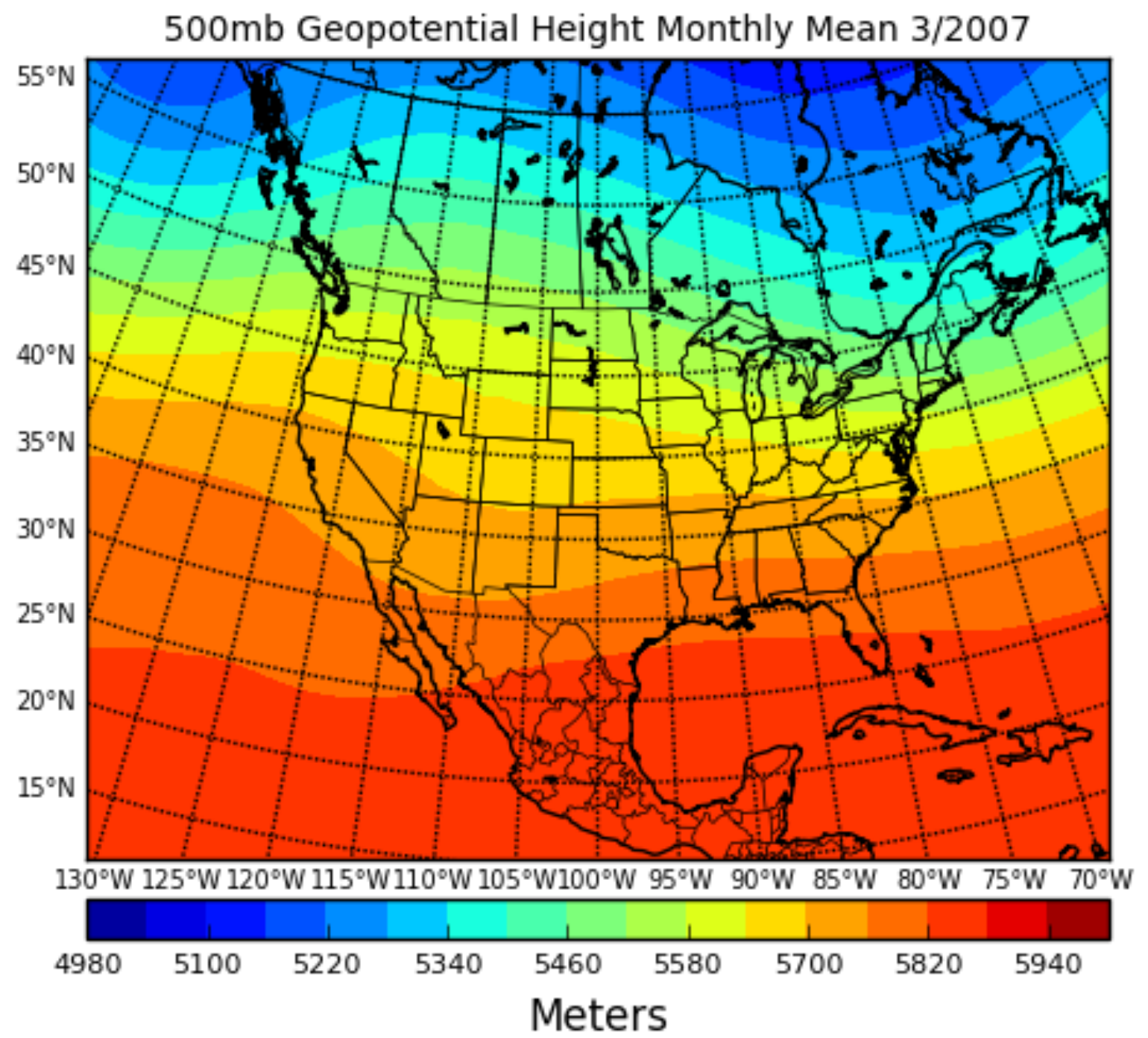

Figure A.14. March $2007\left(+5.2^{\circ} \mathrm{C}\right) 500 \mathrm{mb}$ averaged chart. Persistent zonal flow across the nation leads to an abrupt end of winter throughout the cUSA region. 


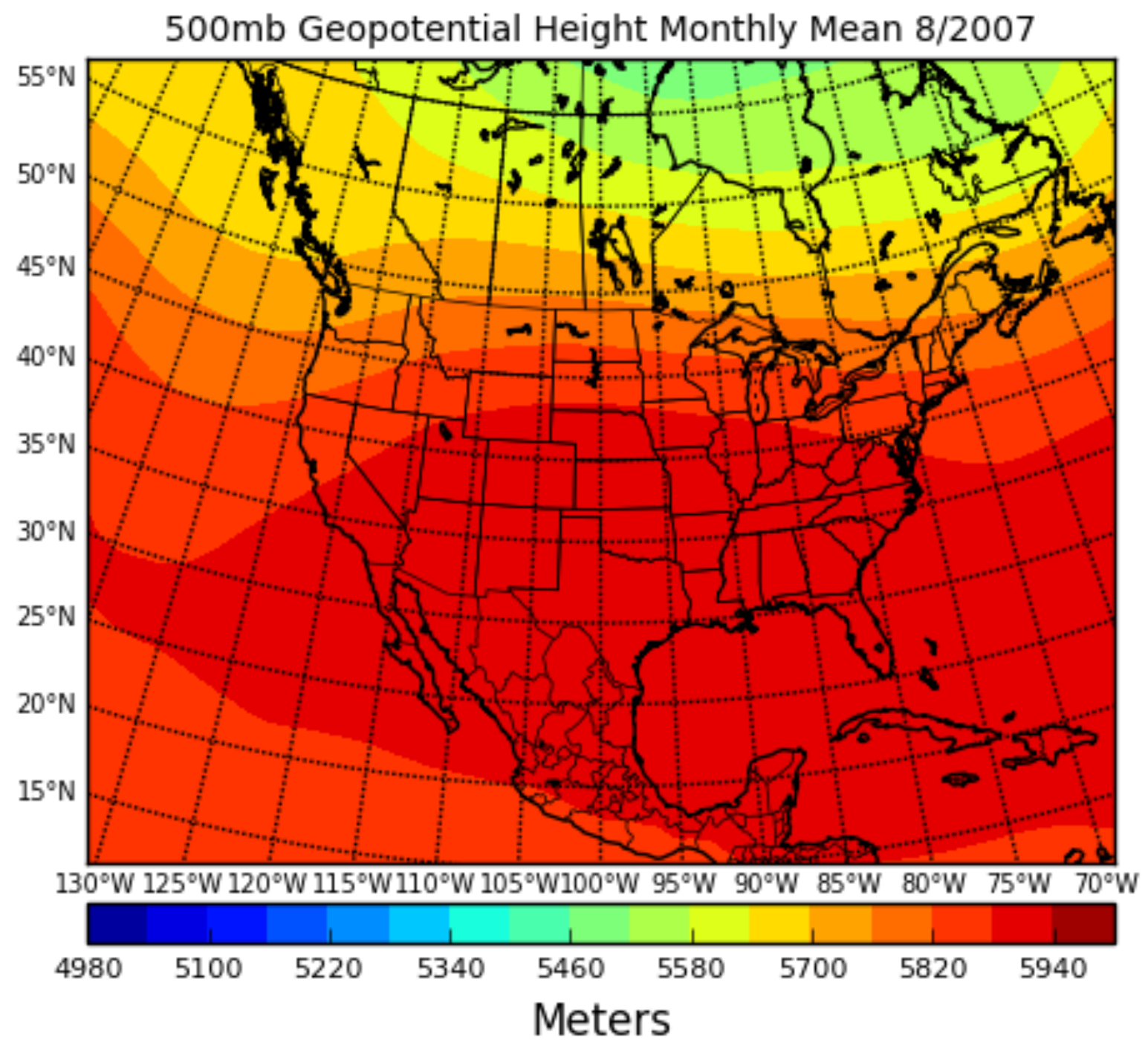

Figure A.15. August $2007\left(+3.6{ }^{\circ} \mathrm{C}\right) 500 \mathrm{mb}$ averaged chart. A high sustained height value across the cUSA for the month August and zonal flow patterns result to a extended summer. 


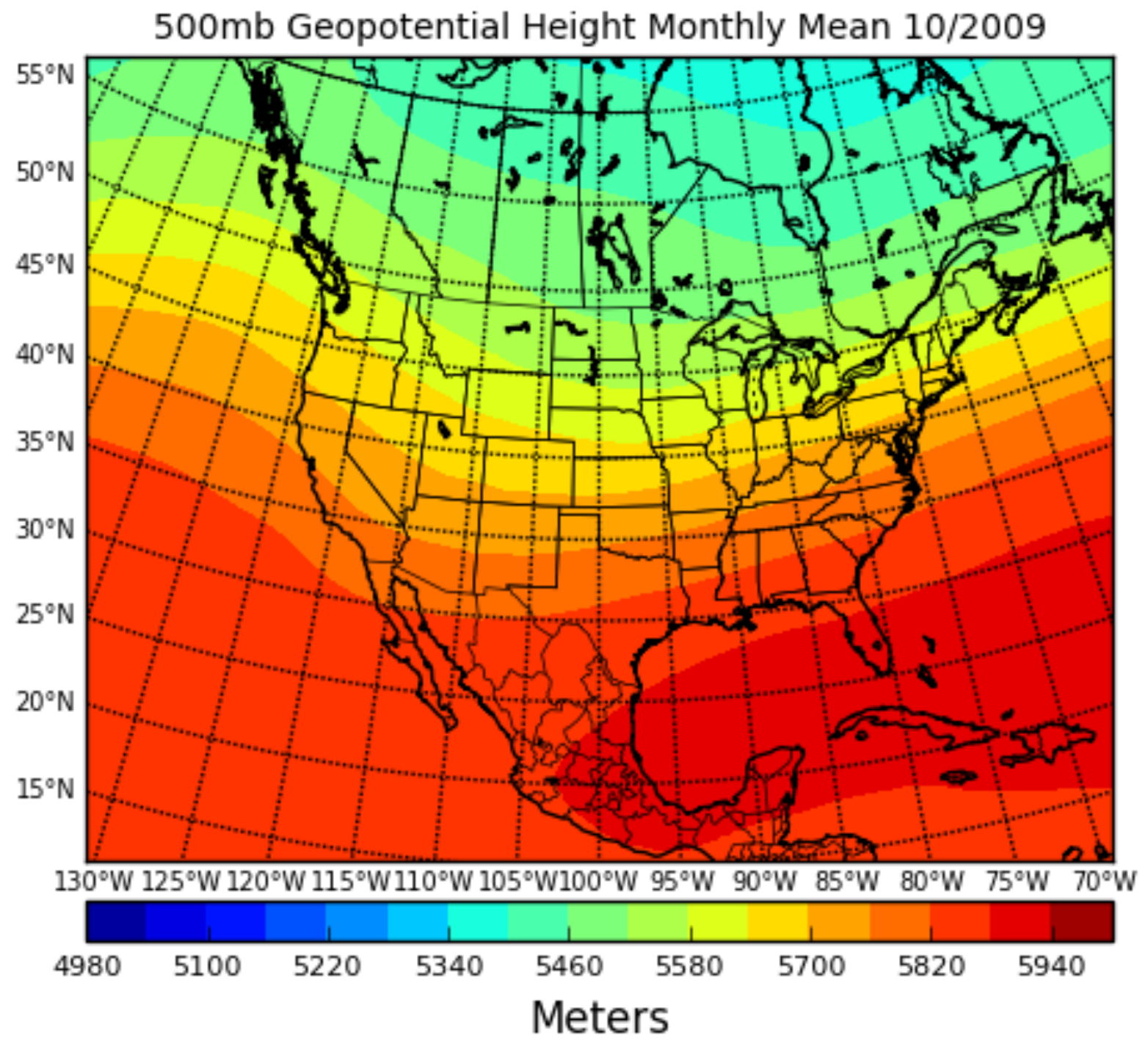

Figure A.16. October $2009\left(-3.7^{\circ} \mathrm{C}\right) 500 \mathrm{mb}$ averaged chart. A meridional flow spreads across the nation with a ridge over the Pacific and a trough in Colorado, leading to a lower temperature flow throughout the cUSA. 


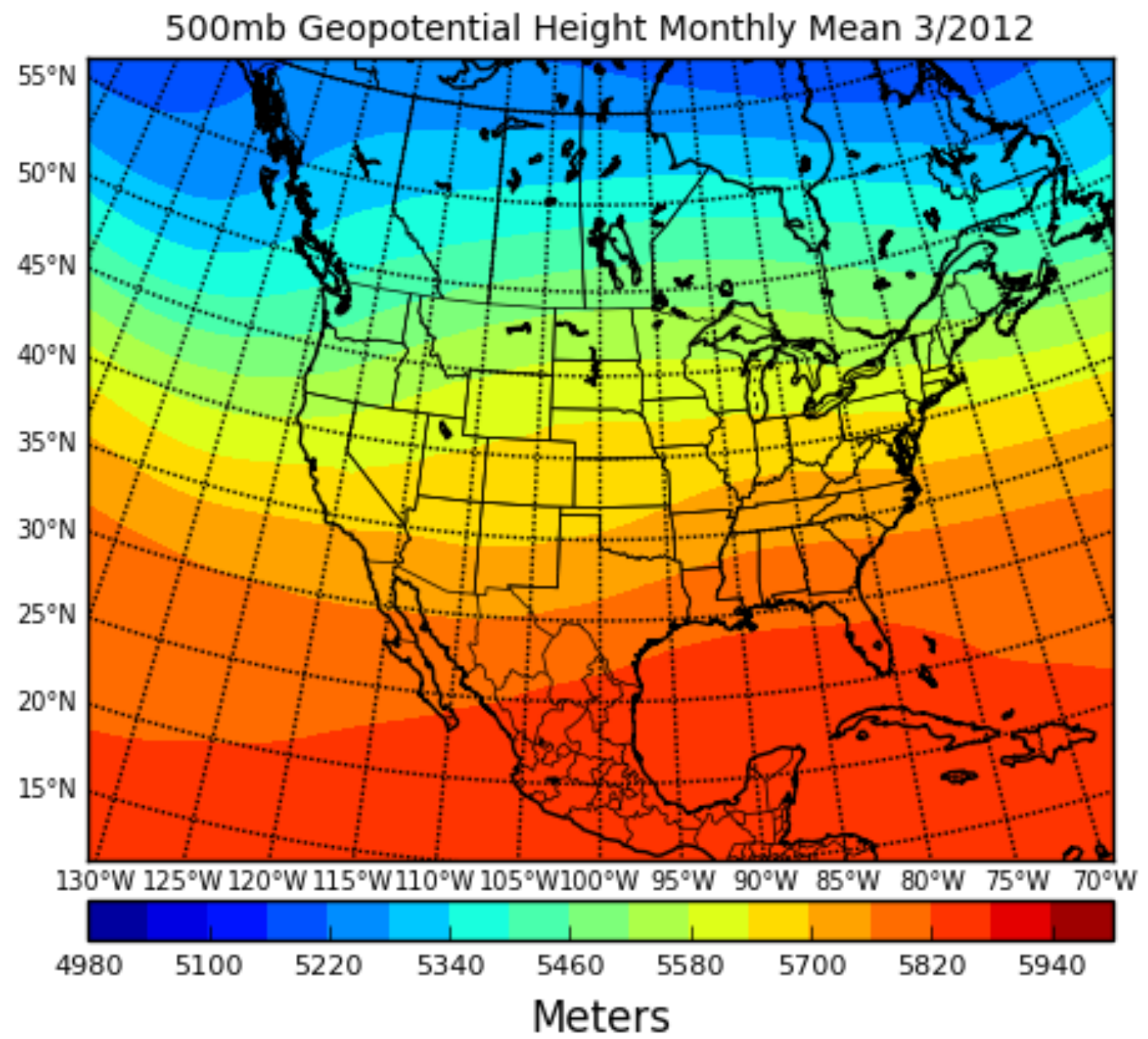

Figure A.17. March $2012\left(+9.0^{\circ} \mathrm{C}\right) 500 \mathrm{mb}$ averaged chart. As elaborated upon in Chapter 4 and Figure $4.4 \mathrm{~B}$, this is the hottest March on record due to a strong anomalous Westerly flow and higher height values. 


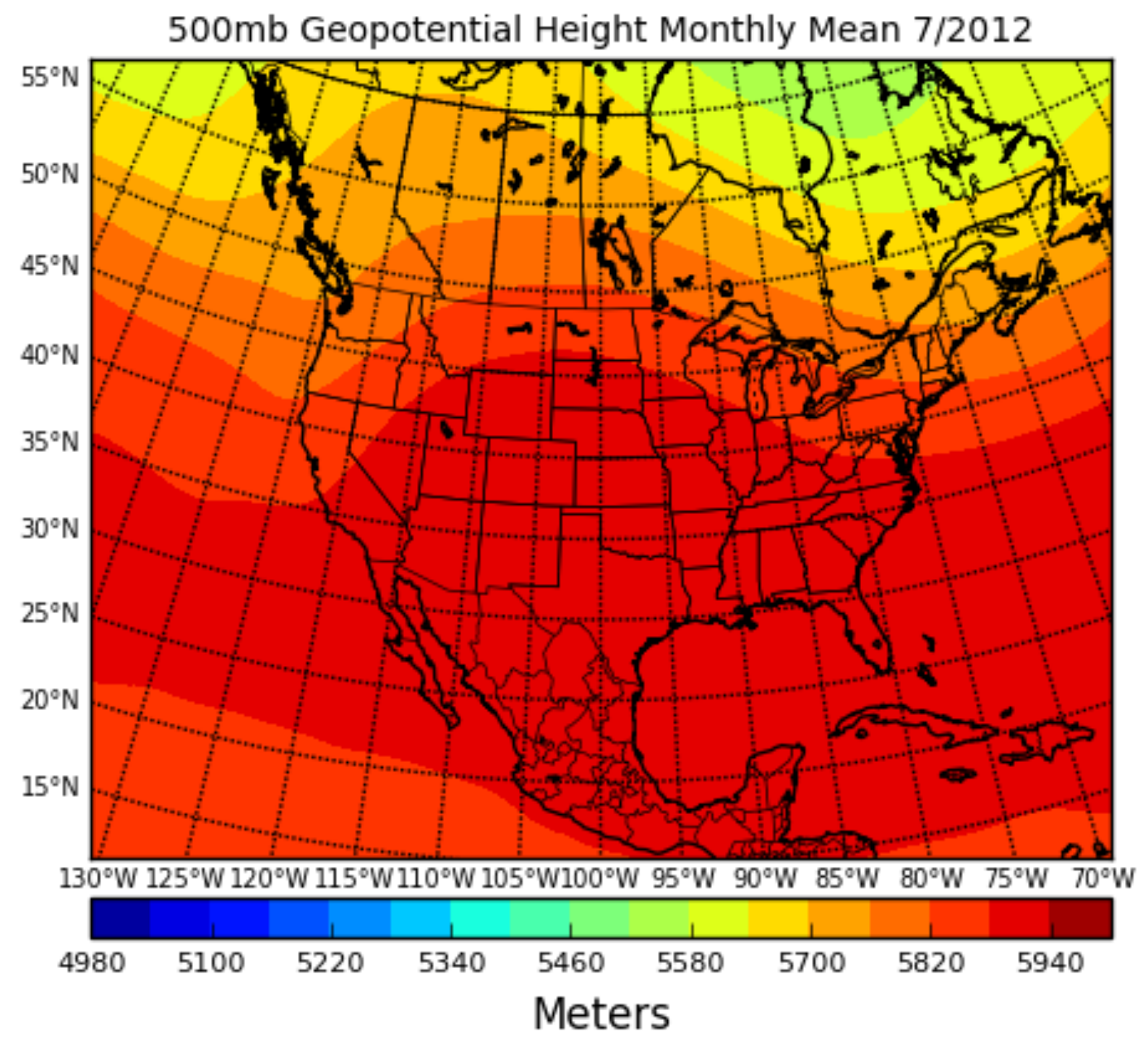

Figure A.18. July $2012\left(+4.2^{\circ} \mathrm{C}\right) 500 \mathrm{mb}$ averaged chart. A more severe case then Figure A.2., as this summer month set blazing records for not only the cUSA region, but across the entire nation. The country was locked underneath an absurdly high zonal flow region. 


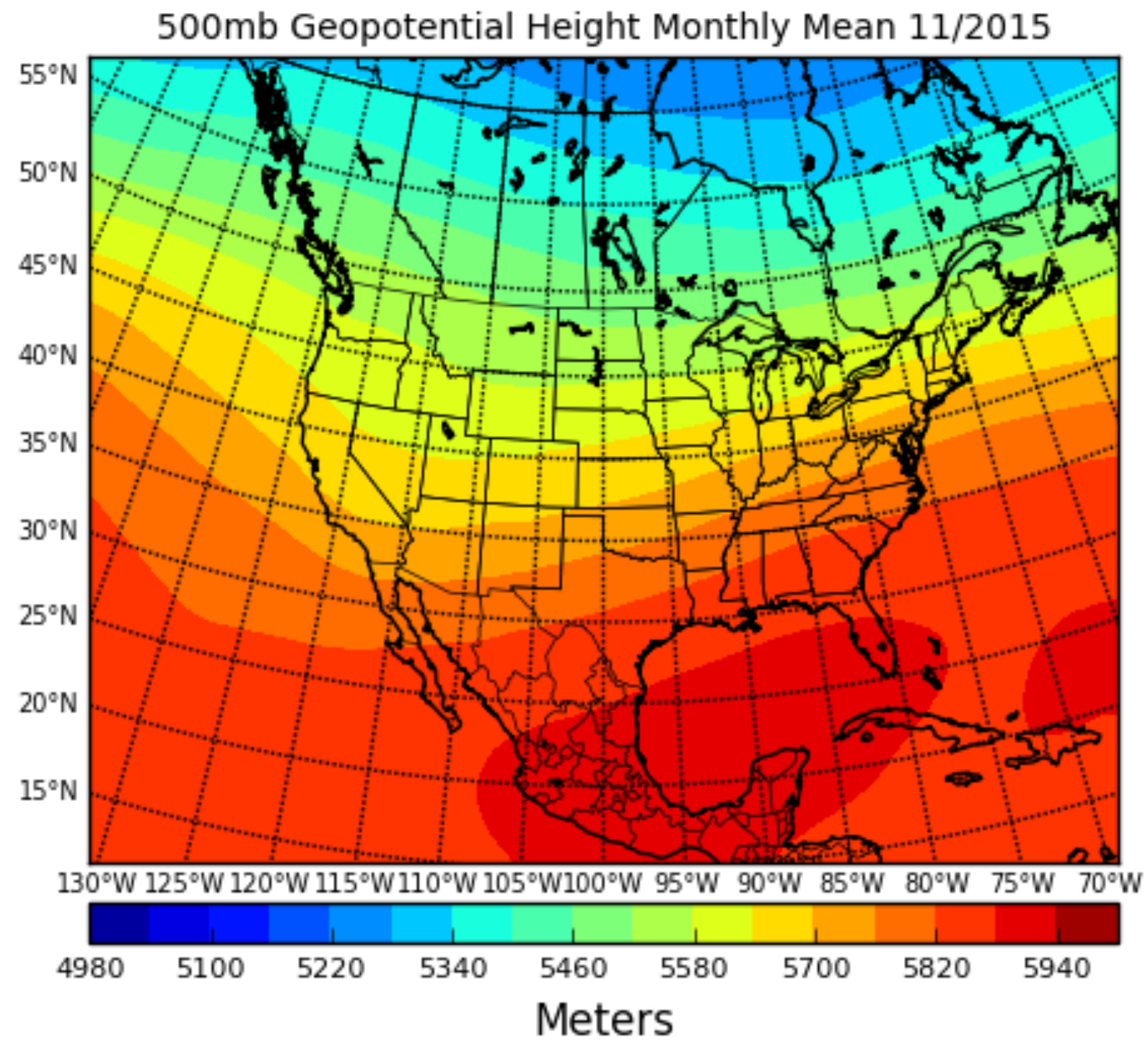

Figure A.19. November $2015\left(+4.2^{\circ} \mathrm{C}\right) 500 \mathrm{mb}$ averaged chart. A digging trough that formed along the Californian Coast made way for a smooth zonal airflow to affect the cUSA region most of the month. 


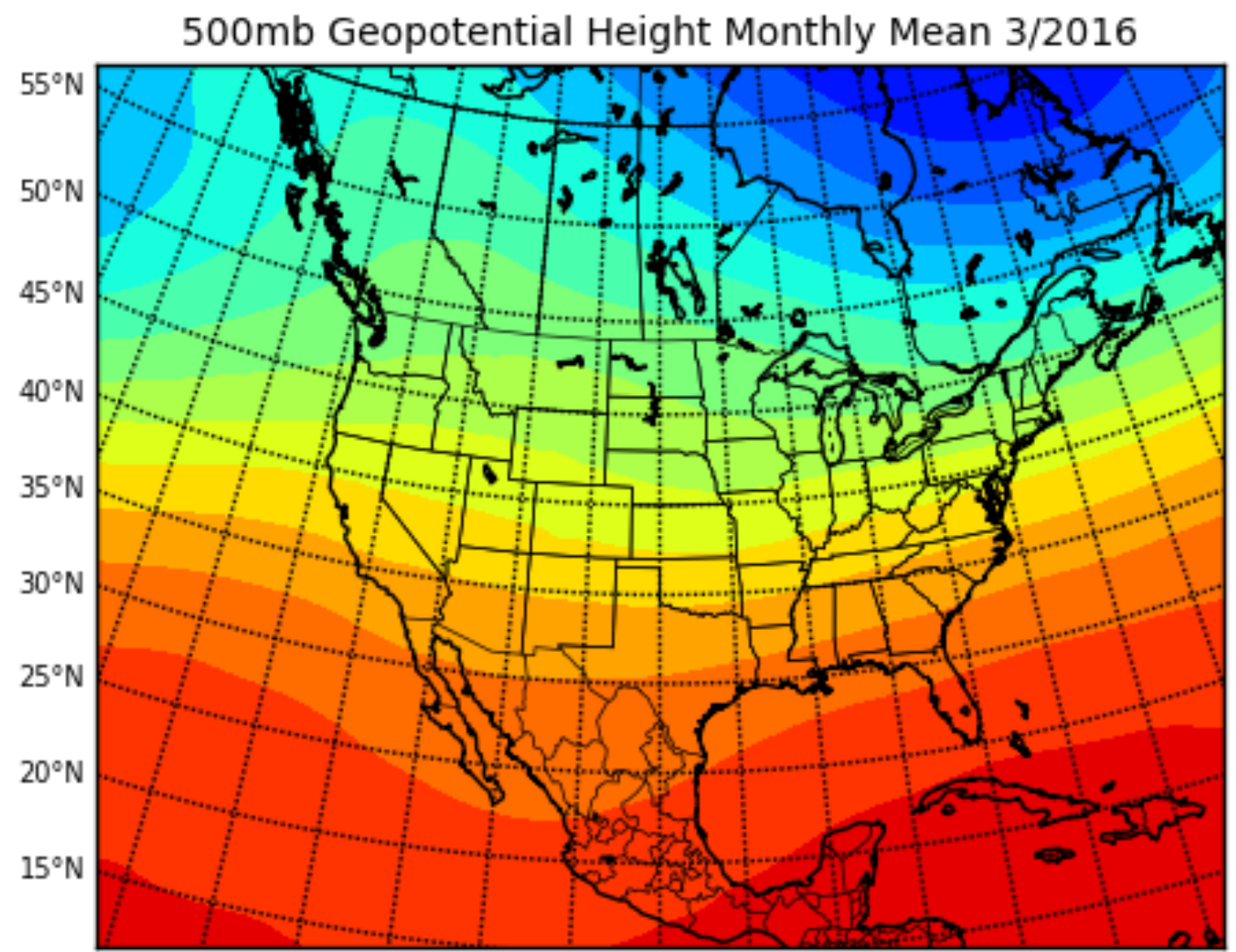

$130^{\circ} \mathrm{W} 125^{\circ} \mathrm{W} 120^{\circ} \mathrm{W} 115^{\circ} \mathrm{W} 110^{\circ} \mathrm{W} 105^{\circ} \mathrm{W} 100^{\circ} \mathrm{W} 95^{\circ} \mathrm{W} \quad 90^{\circ} \mathrm{W} \quad 85^{\circ} \mathrm{W} \quad 80^{\circ} \mathrm{W} \quad 75^{\circ} \mathrm{W} \quad 70^{\circ} \mathrm{W}$

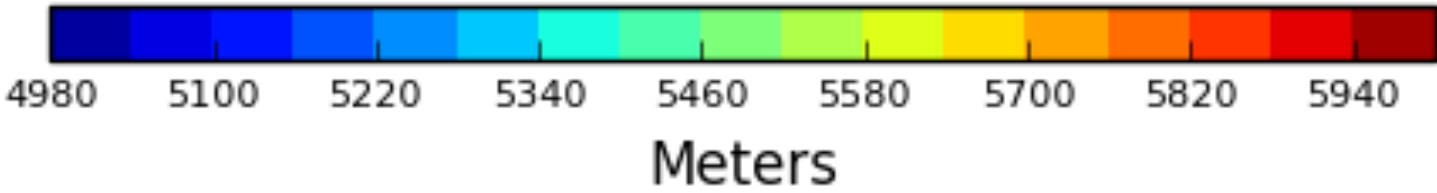

Figure A.20. March $2016\left(+4.4^{\circ} \mathrm{C}\right) 500 \mathrm{mb}$ averaged chart. The most recent warm March, the cUSA was locked under a mild zonal flow, raising temperatures throughout the month. 


\section{REFERENCES}

Abraham, J.J., An analysis of northern hemisphere block sizes compared to climatology and seasonal variations. Univ. of Missouri., (2012).

Akyuz, F.A., M.D. Chambers, and A.R. Lupo, The short and long-term variability of F2 or stronger (significant) tornadoes in the Central Plains. Trans. MO Acad. Sci., vol. 38, 26 - 45 (2004).

Birk, K., A. R. Lupo, P. E. Guinan, and C. E. Barbieri, The interannual variability of midwestern temperatures and precipitation as related to the ENSO and PDO. Atmosfera, vol. 23, 95-128 (2010).

COAPS: Center for Ocean Atmosphere Prediction Studies. ENSO Index According to JMA SSTA (1868-present). Florida State University, accessed on June 30 ${ }^{\text {th }}, 2016$. [Available online at http://coaps.fsu.edu/jma]

ESRL: $20^{\text {th }}$ Century Reanalysis. NOAA, accessed on June $30^{\text {th }}, 2016$. [Available online at https://www.esrl.noaa.gov/psd/data/20thC_Rean/]

ESRL: NCEP North American Regional Reanalysis: NARR Pressure level. NOAA, accessed December $30^{\text {th }}, 2016$. [Available online at https://www.esrl.noaa.gov/psd/data/gridded/data.narr.pressure.html

Gershonov, A., and T.P. Barnett, Interdecadal modulation of ENSO teleconnections. Bull. Amer. Meteor. Soc, vol. 79, 2715 - 2725 (1998).

GCC: Global Climate Change Group. Archive or Log of Northern and Southern Hemisphere Blocking and NAO eras. [Available online at http://weather.missouri.edu/gcc/]

Hagen, T.E., J.M. Glisan, A.R. Lupo, E.M. Aldrich, P.E. Guinan, P.S. Market, and N.I. Fox, The presentation of precipitation information in television broadcasts: What is normal? Nat. Wea. Dig., vol. 34:1, 3-12 (2010).

Hakkinen, S., P.B. Rhines, and D.L. Worthen, Atmospheric blocking and Atlantic Multidecadal OceanVariability. Science, vol. 334 655-659 (2011).

Intergovernmental Panel on Climate Change (IPCC), Climate Change 2013: The Physical Scientific Basis, Contributions of Working Group I to the Fifth Assessment Report of the Intergovernmental Panel on Climate Change. http://www.ipcc.ch. 
Intergovernmental Panel on Climate Change (IPCC), Climate Change 2014: Impacts, Adaptation, and Vulnerability, Contributions of Working Group II to the Fifth Assessment Report of the Intergovernmental Panel on Climate Change. http://www.ipcc.ch. (2014).

Jensen, A.D., Dynamic analysis of a record breaking winter season blocking event. $A d v$ Met, vol. 2015: Article ID 634896, 10 pages (2015)

JISAO: Joint Institute for the Study of the Atmosphere and the Ocean. The Pacific Decadal Oscillation (1900 - present). University of Washington, accessed on March $1^{\text {st }}, 2017$. [Available online at http://research.jisao.washington.edu/pdo/]

Johnstone, J.A., and N.J. Mantua, Atmospheric controls on northeast Pacific temperature variability and change 1900-2012, Proc. Nat. Acad. Sci., doi: 10.1073/pnas.1318371111 (2014).

Kylyshtorin, L.B., A.A. Lyubushin, Cyclic Climate Changes and Fish Productivity. Science Report, Moscow, Russia 230 pp. (2007).

Lebedeva, M.G., O.V. Krymckaya, A.R. Lupo, Y.G. Chendev, A.N. Petin, A.B. Solovyov, Trends in summer season climate for Eastern Europe and Southern Russia in the early $21^{\text {st }}$ century. Adv. Meteor., Sp. Issue: Large Scale Dynamics, Anomalous Flows, and Teleconnections, Vol. 2016, 10 pp. Article ID: 5035086. (2016)

Lupo, A.R., N.B. Smith, P.E. Guinan, and M.D. Chesser, The climatology of Missouri region dew points and the relationship to ENSO. Nat. Wea. Dig., vol. 36:2, 10-20 (2012a).

Lupo, A.R., I.I. Mokhov, M.G. Akperov, A.V. Chernokulsky, and A. Hussain, A dynamic analysis of the role of the planetary and synoptic scale in the summer of 2010 blocking episodes over the European part of Russia. Adv. Meteor., Vol. 2012, Article ID 584257, 11 pages (2012b).

Lupo, A.R., and P. J. Smith, 1995: Climatological features of blocking anticyclones in the Northern Hemisphere. Tellus, 47A, 439-456.

Lupo, A.R., Interannual and Interdecadal variability in hurricane activity. Hurricane Research, ISBN 978-953-307-238-8, Intech Publishers, Vienna. (Book Chapter) Lupo,A.R. Book editor, Recent Hurricane Research: Climate, Dynamics, and Societal Impacts, 616 pp (2011).

Lupo, A.R., K. Latham, T. Magill, J.V. Clark, C.J. Melick, and P.S. Market, The interannual variability of hurricane activity in the Atlantic and East Pacific regions. Nat. Wea. Dig., vol. 32:2 119-135 (2008a).

Lupo, A.R., E.P. Kelsey, D.K. Weitlich, N.A. Davis, and P.S. Market, Using the monthly 
classification of global SSTs and $500 \mathrm{hPa}$ height anomalies to predict temperature and precipitation regimes one to two seasons in advance for the Mid-Mississippi Region. Nat. Wea. Dig., vol. 32, 11-33 (2008b).

Lupo, A.R., E.P. Kelsey, E.A. McCoy, C.E. Halcomb, E. Aldrich, S.N. Allen, A. Akyuz, S.Skellenger, D.G. Bieger, E. Wise, D. Schmidt, and M. Edwards, The presentation of temperature information in television broadcasts: What is normal? Nat. Wea. Dig., vol. 27:4, 53 -58 (2003).

Lupo, A.R., and L.F. Bosart, An analysis of a relatively rare case of continental blocking. Quart J Roy. Meteor. Soc., vol. 125, 107 - 138 (1999).

Marzban, C., and J.T. Schaefer, The correlation between US tornadoes and Pacific Sea Surface Temperatures. Mon. Wea. Rev., vol. 129, 884-895 (2001).

Mokhov, I.I., M.G. Akperov, M.A. Prokofyeva, A.V. Timazhev, A.R. Lupo, H. LeTreut, Blockings in the Northern Hemisphere and Euro-Atlantic region: Estimates of changes from reanalyses data and model simulations. Doklady, vol. 449, 430-433 (2012).

Namias, J., Anatomy of great plains protracted heat waves (especially the 1980 U.S. summer drought). Mon. Wea. Rev., vol. 110, 824 - 838 (1982).

Namias, J., Some causes of the United States drought. J. Clim. and Appl. Met., vol. 22, 30 - 39. (1983).

National Academy of Sciences (NAS), Attribution of Extreme Weather Events in the Context of Climate Change. Report of the National Academy of Sciences, National Academies Press. (2016).

NCEI, 2015: North Atlantic Oscillation. NOAA, accessed November 20 ${ }^{\text {th }}, 2016$. [Available online at https://www.ncdc.noaa.gov/teleconnections/nao/]

Newberry, R., An analysis of the spring-to-summer transition in the west central Missouri Ozarks. Univ. of Missouri., (2014).

Quiroz, R.S., The climate of the 1983-1984 winter. A season of strong blocking and extreme cold in North America. Mon. Wea. Rev., vol. 112, 1894-1912 (1984).

Swanson, K.L., and A. A. Tsonis, Has climate recently shifted? Geophys. Res. Lett., vol. 36, L06711, doi:10.1029/2008GL037022. (2009).

Wiedenmann, J.M., A.R. Lupo, I.I. Mokhov, and E.A. Tikhonova, The climatology of blocking anticyclones for the Northern and Southern Hemispheres: Block Intensity as a diagnostic, J. Clim., vol. 15, 3459-3473 (2002). 
Zuki, Md. Z., and A.R. Lupo, The interannual variability of tropical cyclone activity in the southern South China Sea. J. Geophys. Res., vol. 113, D06106, doi:10.1029/2007JD009218-14 pp (2008). 